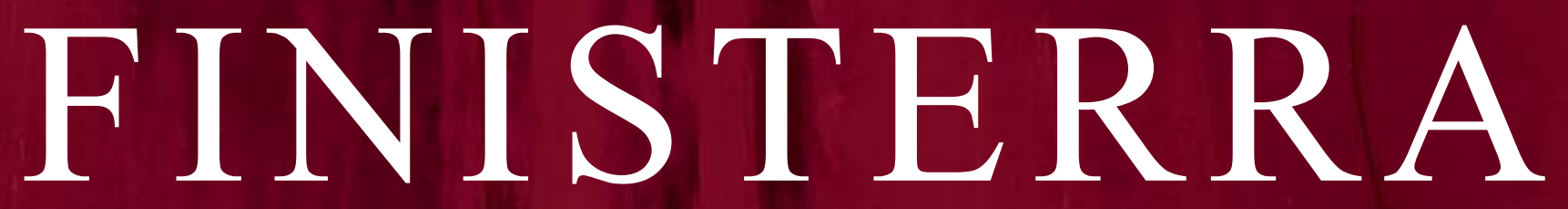

Revista Portuguesa de Geografia

Centro

de Estudos

Geográficos

Volume LII

Número 106

Dezembro 2017 


\title{
LA CONSTRUCCIÓN DE INFRAESTRUCTURAS DE TRANSPORTE EN ESPAÑA: COMPLEJA REALIDAD TERRITORIAL Y DEVENIR INCIERTO
}

\author{
José-María Serrano-MartíneZ ${ }^{1}$ \\ RAMÓN GARCÍA-MARÍN ${ }^{2}$
}

\begin{abstract}
RESUMEN - Durante el transcurso de los últimos veinticinco años, el aumento y mejora de las infraestructuras de transporte en España ha sido evidente. La obra civil, entre la que se incluyen las infraestructuras de transporte, aguantó los primeros compases de la crisis reciente gracias a la implementación inmediata de un paquete público de proyectos de ingeniería civil. Sin embargo, desde 2010, el gasto en infraestructuras por parte de la Administración pública se desplomó como medida para conseguir los objetivos de déficit exigidos. En este trabajo se realiza un análisis evolutivo de los diferentes modos de transporte (en especial, tráfico de pasajeros, para puertos mercancías) y las inversiones realizadas para mejorar sus infraestructuras. Se aprecian ciertas sobredotaciones, algunos excesos y puntuales disarmonías. Finalmente, se realizan algunas reflexiones y consideraciones sobre la distribución territorial del gasto público en infraestructuras de transporte, endeudamiento y disponibilidades económicas futuras. Tal vez sería conveniente introducir una nueva política de infraestructuras para hacer frente a los numerosos retos que se presentan en un horizonte inmediato.
\end{abstract}

Palabras clave: Construcción; infraestructuras de transporte; crisis; inversión; territorio.

RESUMO - A CONSTRUÇÃO DE INFRAESTRUTURAS DE TRANSPORTE EM ESPANHA: REALIDADE TERRITORIAL COMPLEXA E FUTURO INCERTO. Durante o transcurso dos últimos vinte e cinco anos, é evidente o aumento e melhoria da infraestrutura de transporte em Espanha. A construção civil, na qual se inclui a infraestrutura de transporte, suportou a fase inicial da crise recente graças à implementação imediata de um

Recebido: fevereiro 2017. Aceite: setembro 2017.

1 Profesor Catedrático del Departamento de Geografía de la Facultad de Letras de la Universidad de Murcia, Santo Cristo $n^{\circ} 1$, 30001 Murcia, España. E-mail: jmserran@um.es

2 Profesor contratado del Departamento de Geografía de la Facultad de Letras de la Universidad de Murcia, Santo Cristo n 1 , 30001 Murcia, España. E-mail: ramongm@um.es 
pacote público de projetos de engenharia civil. Porém, desde 2010, os investimentos em infraestrutura por parte da administração pública declinaram para atingir os objetivos de défice exigidos. Neste trabalho é realizada uma análise evolutiva dos diferentes meios de transporte (tráfego de passageiros e de mercadorias nos portos), bem como o levantamento dos investimentos efetuados para melhorar as infraestruturas. São identificadas dotações sobrestimadas, alguns excessos e desarmonias pontuais. Finalmente, são realizadas algumas reflexões e considerações sobre a distribuição territorial das despesas públicas em infraestrutura de transporte, endividamento e disponibilidades económicas futuras. Uma nova política de infraestruturas deverá contemplar muitos dos desafios que se apresentam no futuro imediato.

Palavras-chave: Construção; infraestrutura de transporte; crise; investimento; território.

ABSTRACT - THE CONSTRUCTION OF TRANSPORT INFRASTRUCTURES IN SPAIN: A COMPLEX TERRITORIAL REALITY AND AN UNCERTAIN FUTURE. Over the last twenty-five years, there has been an improvement and increase in the transport infrastructure in Spain. Civil works, including transport infrastructures, withstood the first impacts of the recent crisis thanks to the immediate implementation of a public package of civil engineering projects. However, since 2010, spending on infrastructure by the public administration has collapsed as a measure to achieve the required deficit targets. In this paper, we perform an evolutionary analysis of the different modes of transport (passenger and goods traffic for ports) and the investments made to improve its infrastructures. Among the results, we identify some excesses and punctual disharmonies. Finally, some reflections and considerations are made on the territorial distribution of public expenditure on transport infrastructures, indebtedness and future economic availability. A new infrastructure policy will have to face the many challenges that arise in the immediate future.

Keywords: Construction; transport infrastructures; crisis; investment; territory.

RÉSUMÉ - LA CRÉATION D’INFRASTRUCTURES DE TRANSPORT EN ESPAGNE: UNE RÉALITÉ TERRITORIALE COMPLEXE, UN FUTUR INCERTAIN. Au cours des 25 dernières années, l'Espagne a connu une nette amélioration de ses infrastructures de transport. La construction civile a bien résisté, en général, à la phase initiale de la crise récente, grâce à la rapide mise en œuvre d'un ensemble de projets publics de génie civil. Mais, depuis 2010, les investissements en infrastructures de l'administration ont diminué, à cause des limites de déficit exigés. On a réalisé ici une analyse de lévolution de divers moyens de transport (le trafic des passagers et des marchandises dans les ports) et on a compilé l'importance des investissements effectués pour améliorer leurs infrastructures). On a ainsi pu déceler des dotations surestimées ainsi que quelques excès et déséquilibres ponctuels. On présente finalement quelques réflexions sur la répartition territoriale des dépenses publiques en infrastructures de transport, sur l'endettement et sur les disponibilités financières futures. Toute nouvelle politique d'infrastructures devra faire face, dans un futur très proche, à de nombreux défis.

Mots clés: Construction; infrastructure de transport; crise; investissement; territoire. 


\section{INTRODUCCIÓN Y PLANTEAMIENTO}

Tras la crisis económica, a partir de 2008, se hunde el conjunto del sector de la construcción en España. Algunos autores consideran que la dimensión alcanzada era excesiva, y en cierta medida había pasado de un medio a un fin en sí misma (Campos, 2008); desde esa óptica se concluye que su aminoración es bienvenida. Pero tal reducción conlleva numerosas consecuencias. Una parte destacada del retroceso del sistema productivo español se debe al derrumbe del subsector de la edificación, en especial de las viviendas (la llamada burbuja inmobiliaria) (Balmaseda, 2002). Pero también el conjunto de la obra civil, entre la que destacan las infraestructuras de transportes, sufren una pronunciada caída. Aquí se parte de la hipótesis de que las inversiones en infraestructuras de transporte presentan un porvenir delicado, pues concurren diversas circunstancias estructurales que barruntan un horizonte, a corto y medio plazo, poco favorable para su recuperación, con los dispares y encontrados desenlaces que de ello se desprenden. Sobre ellas ha recaído buena parte de la reducción del gasto público. Los reajustes económicos han obligado a medidas de restricción significativas. Ahora bien, es arriesgado cargar sobre un apartado tan estratégico y fundamental disminuciones de inversión acusadas, pues conlleva numerosos arrastres negativos. Todo ello aconseja calibrar bien cuales van a ser los destinos preferentes de inversión de los dineros públicos. Sin duda, es necesario articular una racional política global de infraestructuras, ajustada y efectiva, priorizando aquellas más necesarias, con atención en sus aspectos sectoriales y territoriales, y acorde con las necesidades presentes y futuras, junto a pertinentes controles de inversión. Las mejoras realizadas en años pasados han sido muchas y han incrementado sustancialmente los equipamientos disponibles (Segura, 2013). De la misma manera, el análisis ponderado de lo hecho debe servir de marco de referencia para no cometer errores anteriores, numerosos y variados. Sobre todo, pensando que, en adelante, las disponibilidades inversoras no son presumibles que alcancen cifras tan cuantiosas como las precedentes; entre otras causas, por los elevados niveles de endeudamiento acumulados (Vergés, 2013). Todo lo cual puede lastrar el crecimiento económico general. Un tema muy complejo sobre el que es oportuno reflexionar. Ello nos sitúa en la tesitura de, además de calibrar bien las posibilidades de mantener ciertos niveles de inversión, dirigirlos hacia los aspectos prioritarios, dejando de lado aquellos otros que no lo son. Pero, eso implica ser conscientes de las consecuencias que comporta una actividad inversora en infraestructuras de transporte menor, que conducirá a una atonía del sector y mitigará el relanzamiento del sistema productivo general. Conviene no olvidar la elevada proporción de retornos implícitos en tales inversiones; las cuales, a su vez, precisan una actividad relativamente poco intensiva en importaciones. Y eso también favorece nuestra economía.

La dimensión territorial de todo ello es innegable. Desde la geografía es posible realizar acertadas consideraciones. Toda política de infraestructuras tiene una plasmación espacial concreta. La armonía entre las regiones no puede impedir ni condicionar los intereses generales del conjunto del territorio del Estado. Si bien debe buscarse un 
equilibrio territorial, no será posible cribarlo todo desde una óptica regional predominante. Eso conduciría a la inoperancia.

Aminorar un ciclo de actividad inversora expansivo, como han tenido las infraestructuras de transportes, conlleva, pues, sus consecuencias. Si bien no es conveniente, ni adecuado, proseguir con un auge inversor en infraestructura como modo de sostener el crecimiento económico, tampoco resulta sencillo encontrar otras alternativas de sustitución. Pero, el ciclo expansivo de estos apartados mantenido durante años, parece ya lejano.

\section{ESTADO DE LA CUESTIÓN Y METODOLOGÍA}

La importancia sobresaliente de la construcción encierra una significación económica destacada (Taltavull, 2001; García \& Mas, 2004). Dentro de ella, el apartado de los transportes y sus infraestructuras ha sido objeto de numerosos estudios a partir de años pasados y con dispares puntos de vista (Quinet, 1992; Merenne, 1995; Flyvbjerg, Skamris \& Buhl, 2004). Su complejidad se ha enfatizado a menudo (Chesnais, 1997), señalando la especial significación plural de la puesta en servicio de las infraestructuras pertinentes (Gerondeau, 1996). Estas se enfocan, con frecuencia, desde la perspectiva de su contribución al desarrollo regional (Biehl, 1991; Graham, 2005). La dimensión espacial, geográfica, de estos estudios es habitual (Seguí \& Martínez, 2004). Su organización y necesario planeamiento se ha abordado, desde hace tiempo, sobre todo desde la geografía (Merlin, 1991) y la economía (Thomson, 1976; Harvey, 2007). En el caso de España, en años pasados ya se han dedicado a ello numerosos trabajos (García Martínez, 1987; Izquierdo \& Menéndez, 1987). Pero, también recientemente sigue centrando la atención de algunos autores (De Rus, 2015a). El balance del periodo de fuertes inversiones en infraestructuras es dispar: enfatizando su valoración favorable (VV.AA., 2015); frente a otras consideraciones más matizadas (Segura, 2016). Tras unas décadas de auge, la actual coyuntura de vacilación por la que atraviesan estas inversiones centra la atención de los estudiosos (Marsal \& Vilanova, 2013). Tras un pasado cercano en apariencia sólido y seguro (Muñoz, 2013), se advierten incertidumbres con importante sesgo territorial (Segura, 2012; Pérez, 2013). Ese escenario ocupa nuestra atención en el presente estudio, inclinado el análisis hacia el transporte de pasajeros. Por su parte, en algún modo de transporte, como el marítimo, se tiene en cuenta su destacada significación en el tráfico de mercancías.

Un campo tan complejo precisaría una atención pluridisciplinar. Desde la geografía, aunque de manera común se utilizan procedimientos de síntesis, inherentes a la combinación oportuna de escalas territoriales, también se requieren tareas previas de análisis (Cano, 1986).

El artículo se organiza en cuatro apartados. En el primero y anterior se formula el planteamiento del problema y la hipótesis de partida. En este segundo se expone de forma breve información relevante referida al tema de investigación, reflejando el conocimiento 
y las ideas que han establecido otros autores anteriormente. También se explica el proceder en este trabajo. En el tercer apartado se analiza el incremento y mejora de infraestructuras de transporte en España durante el periodo reciente (finales del siglo XX e inicios del XXI). Tras este análisis, en el cuarto apartado, se reflexiona sobre lo acontecido y se plantean una serie de consideraciones sobre el devenir futuro. El empleo de numerosas fuentes de datos, en su mayoría procedentes del Ministerio de Fomento, sirve de apoyo para las observaciones y razonamientos efectuadas. Mayoritariamente se emplean los datos de inversiones referidos a la administración estatal, y sólo puntualmente se completan con otros de ámbitos diferentes. Para evitar un texto plagado de cifras estadísticas se recurre a su representación gráfica y cartográfica, con numerosas figuras que las simplifican y ayudan a su mejor comprensión. La utilización de una amplia bibliografía permite abordar la combinación de elementos de dispar naturaleza, concurrentes en el devenir global de los hechos analizados.

\section{INCREMENTO Y MEJORA DE LAS INFRAESTRUCTURAS DE TRANSPORTE DURANTE LAS ÚLTIMAS DÉCADAS}

Atendiendo a datos absolutos y relativos durante el transcurso de los últimos veinticinco años, el aumento y mejora de las infraestructuras de transporte en España es evidente. Sin duda, se partía de umbrales reducidos donde las carencias eran muchas. Analizar lo acaecido resulta complejo. Una tarea así precisaría un análisis interdisciplinar amplio, combinando elementos técnicos, de ingeniería, económicos, sociales y espaciales. La dimensión y el cambio que todo ello ha supuesto hace posible enfocarlo desde diferentes perspectivas con especial hincapié en unos u otros aspectos, sin dejar de lado las críticas pertinentes hacia sus apartados menos brillantes o negativos. Si bien se advierten ciertos desajustes ocasionados, algunos excesos puntuales y determinadas estrategias sectoriales poco comprensibles, el resultado global es bastante favorable (Feito, 2011).

La inversión realizada ha sido cuantiosa. Dada su duración temporal, diferente procedencia y los dispares mecanismos financieros utilizados, ni siquiera resulta fácil evaluarla de manera ajustada. A menudo, las cifras globales barajadas difieren. También, a veces, su valoración se solapa dentro del conjunto de la actividad global de la construcción y su modelo expansivo (Fernández, 2006). Por eso conviene desagregarla.

Las cifras globales del sector de la construcción son altas, en valores absolutos y en su significación dentro del PIB nacional. Su acusada variación temporal confirma el apogeo del boom constructor y su posterior caída. Conviene señalar la menor variación del apartado ingeniería civil, la cual se mueve dentro de una horquilla situada entre el $21 \%$ y el $31 \%$ del total (cuadro I). Pero, a su vez, de sobra se conoce que la "ingeniería civil" abarca un concepto mucho mayor que la parte circunscrita a infraestructuras de transportes. Esa inversión directa, realizada desde los presupuestos públicos a través del Ministerio de Fomento, sirve de referencia de partida (cuadro II). 
Cuadro I - Volumen de negocio de la actividad de la construcción por tipo de obra (millones de euros), y valores porcentuales.

Table I - Business turnover of construction activity by type of construction (millions of euros), and percentage values.

\begin{tabular}{cccccccc}
\hline Años & $\begin{array}{c}\text { TOTAL } \\
\text { millones de } \\
\text { euros }\end{array}$ & $\begin{array}{c}\text { \% VAB } \\
\text { construcción / } \\
\text { PIB }^{* *} \text { Nacional }\end{array}$ & $\begin{array}{c}\text { Ingeniería } \\
\text { Civil, millones } \\
\text { de euros }\end{array}$ & $\begin{array}{c}\% \\
\text { Promoción } \\
\text { Inmobiliaria }\end{array}$ & $\begin{array}{c}\% \\
\text { Construcción } \\
\text { Residencial }\end{array}$ & $\begin{array}{c}\text { Construcción } \\
\text { No Residencial }\end{array}$ & $\begin{array}{c}\text { \% } \\
\text { Ingeniería } \\
\text { Civil }\end{array}$ \\
\hline 2002 & 173539,7 & 9,83 & 45849,9 & 0,0 & 51,9 & 21,6 & 26,4 \\
2003 & 195131,8 & 9,92 & 46674,7 & 0,0 & 54,1 & 22,0 & 23,9 \\
2004 & 210817,9 & 9,98 & 56031,6 & 0,0 & 53,4 & 20,0 & 26,6 \\
2005 & 247273,9 & 10,38 & 52007,5 & 0,0 & 58,6 & 20,3 & 21,0 \\
2006 & 284831,5 & 10,45 & 72361,1 & 0,0 & 48,6 & 20,3 & 21,0 \\
2007 & 295272,0 & 10,10 & 90802,2 & 0,0 & 49,6 & 19,6 & 30,8 \\
2008 & 231814,7 & 10,14 & 70502,5 & 0,0 & 49,6 & 19,6 & 30,8 \\
2009 & 279789,9 & 9,87 & 65183,6 & 32,1 & 28,4 & 16,1 & 23,3 \\
2010 & 196923,5 & 8,10 & 55842,7 & 19,7 & 31,6 & 20,4 & 28,4 \\
2011 & 151775,7 & 6,91 & 41485,1 & 23,1 & 30,7 & 18,8 & 27,3 \\
2012 & 114957,8 & 5,80 & 30513,6 & 19,8 & 33,5 & 20,2 & 26,5 \\
2013 & 92483,0 & 5,09 & 29053,1 & 14,7 & 32,7 & 21,2 & 31,4 \\
2014 & 87126,1 & 4,93 & 25328,3 & 13,6 & 37,4 & 20,9 & 28,1 \\
2015 & 86325,2 & 5,03 & 24637,2 & 12,8 & 37,6 & 20,4 & 29,2 \\
\hline
\end{tabular}

${ }^{\star} \mathrm{VAB}=$ Valor Añadido Bruto; ${ }^{*} \mathrm{PIB}=$ Producto Interior Bruto

Fuente: Elaboración propia sobre datos del Ministerio de Fomento (2015)

Cuadro II - Evolución de la inversión en infraestructuras de transporte (millones de euros).

Table II - Evolution of investment in transport infrastructures (millions of euros).

\begin{tabular}{cccccr}
\hline Años & Carreteras & Ferrocarril & Aeropuertos & Puertos & Total \\
\hline 1996 & 2349 & 945 & 434 & 337 & 4065 \\
1997 & 2111 & 744 & 516 & 357 & 3728 \\
1998 & 2873 & 943 & 537 & 375 & 4728 \\
1999 & 2424 & 1446 & 544 & 426 & 4840 \\
2000 & 2498 & 1732 & 570 & 415 & 5215 \\
2001 & 2573 & 2481 & 1020 & 516 & 6590 \\
2002 & 2695 & 3490 & 1413 & 545 & 8143 \\
2003 & 2821 & 3558 & 2205 & 706 & 9290 \\
2004 & 2876 & 4136 & 2075 & 791 & 9878 \\
2005 & 3251 & 5245 & 1405 & 908 & 10809 \\
2006 & 4309 & 7770 & 1751 & 1427 & 15257 \\
2007 & 7707 & 8236 & 1988 & 1463 & 19394 \\
2008 & 8037 & 9181 & 2121 & 1635 & 20974 \\
2009 & 6802 & 9854 & 1762 & 1429 & 18847 \\
2010 & 7794 & 8918 & 1732 & 1313 & 19757 \\
2011 & 5926 & 8158 & 1212 & 902 & 16198 \\
2012 & 5270 & 5636 & 938 & 564 & 12408 \\
2013 & 4603 & 2903 & 578 & 511 & 8595 \\
2014 & 4227 & 3213 & 358 & 487 & 8285 \\
$2015^{*}$ & 4182 & 2838 & 293 & 1100 & 8413 \\
$1996-2015$ & 85328 & 91427 & 23452 & 16207 & 215414 \\
\hline
\end{tabular}

Fuente: Ministerio de Fomento, Anuarios Estadísticos. $\left(^{*}\right)$ Los datos de 2015 son provisionales 
Los datos anteriores, no obstante, deben tomarse con cierta cautela, en lo referido a su anualidad de ejecución. A veces, ciertas cantidades señaladas, si bien se destinan directamente a ese fin, se emplean en cubrir gastos generados antes.

El periodo prolongado de veinte años señala su cumbre de inversiones entre $2007 \mathrm{y}$ 2009. El descenso posterior es claro y progresivo. El último año de referencia sólo significa el 39,60\% del valor de 2008. Pero, aun así, 2014 todavía representa el doble del inicio del ciclo (1996). Eso confirma cierta resistencia de las autoridades españolas por mantener sus programas de inversiones en infraestructuras de transportes. Es interesante comprobar la dispar cantidad dedicada a los diferentes modos del transporte y su disímil temporización. Carretera y ferrocarril son los más beneficiados. A su vez, la apuesta por el ferrocarril crece a partir de 2001, mientras que las inversiones en carreteras han sido más regulares.

Las consecuencias de las recientes reducciones de inversión se han dejado sentir en las empresas del sector, y sus arrastres derivados han sido cuantiosos, con consecuencias económicas, laborales, etc. Son numerosas las opiniones vertidas sobre esa cuestión, enfocadas desde diversos puntos de vista. Cada uno con sus criterios e intereses. Unos defienden el mantenimiento y ascenso de tales inversiones, pues eso favorece las necesidades globales españolas y los beneficios empresariales (VV.AA., 2013). Otros, consideran que, alcanzada cierta dotación de tales equipamientos, deben reducirse las actuaciones futuras (López \& Rodríguez, 2010). No faltan quienes consideran que proseguir con nuevas obras de infraestructuras de transportes favorece un impulso artificial para sostener el crecimiento económico, una burbuja que hay que desinflar (Sanz Vega \& Mateos, 2016). Una posición más equilibrada se obtiene al comparar el grado de equipamiento español con el de nuestros vecinos (fig. 1).

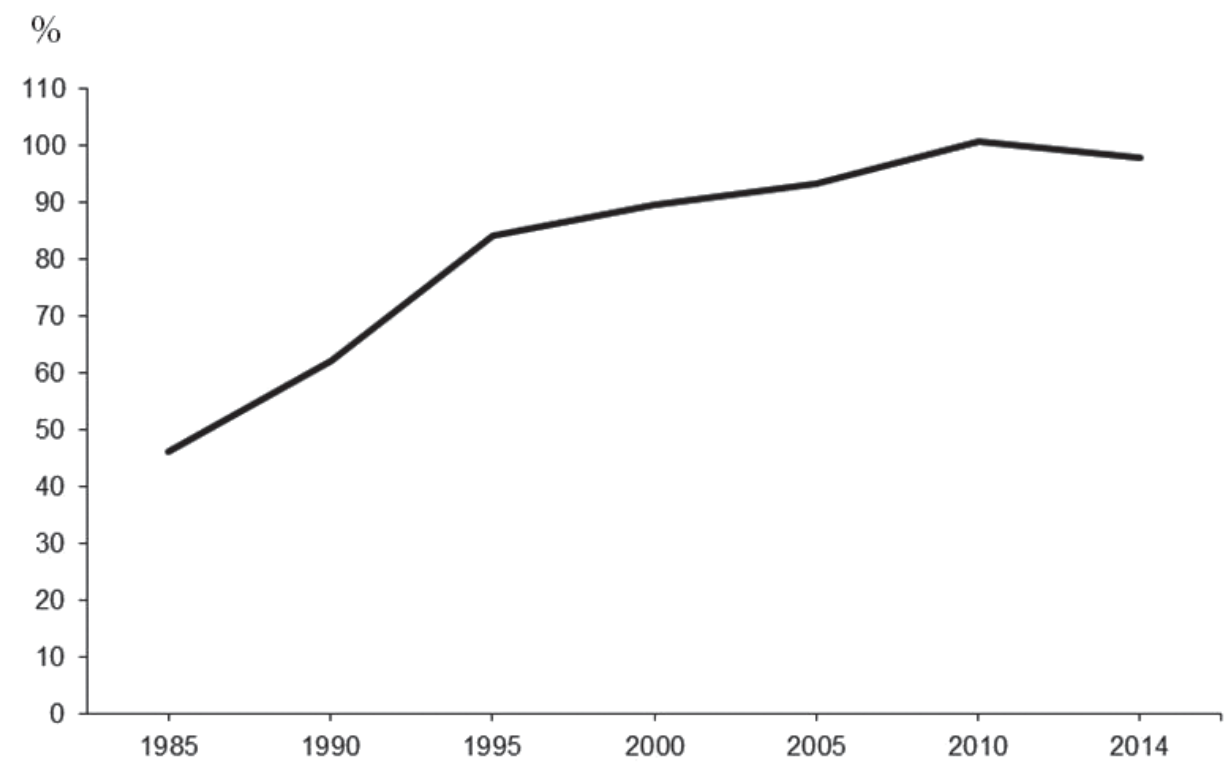

Fig. 1 - Evolución en porcentaje del nivel de infraestructuras de transporte por habitante en España respecto a la media de la Unión Europea (100).

Fig. 1 - Evolution in the percentage of the level of transport infrastructures per inhabitant* in Spain with respect to the average of the European Union (100).

* Parámetro teórico que evalúa los equipamientos en infraestructuras de transporte, la fluidez de sus desplazamientos y su accesibilidad en relación con la población Fuente: Elaboración propia a partir de: VV.AA. $(2016$, p. 6) 
En la figura 1 se observa claramente el acusado déficit inicial de partida. Era un rasgo común enfatizado en manuales de antaño (Tamames, 1964). La recuperación alcanzada es indiscutible, pero calificarla en general de sobredotación parece excesiva. Lo cual no empece para que el análisis modal de los transportes en casos y apartados particulares muestre ciertas sobredotaciones, algunos excesos, puntuales disarmonías, superposiciones y variadas relaciones equívocas de coste-beneficio.

\section{Resultados modales}

Tras la presentación y discusión de ciertos aspectos generales, procede fijarse en elementos concretos, siguiendo los básicos modos de transporte. Cada uno partía de umbrales diferentes, si bien era rasgo común su situación deficitaria. Por ello, para alcanzar una visión global de lo realizado es oportuno realizar un sucinto análisis y discusión de cada uno. Interesa fijarse en sus resultados y problemáticas singulares, las cuales condicionaran las futuras inversiones.

A) Las carreteras constituyen un apartado esencial, tanto por su dimensión, como por las funciones predominantes en el tráfico de pasajeros y mercancías. La red conjunta de vías (consideradas como carreteras) supera los $166000 \mathrm{~km}$. atendiendo a sus diversos ámbitos (locales, provinciales, regionales y nacionales). En muchas de ellas se han realizado mejoras en el firme y corrección de sus trazados. Pero, sin duda, son las denominadas vías rápidas de gran capacidad (VRGC) las que muestran un balance más llamativo (fig. 2).

Durante los últimos veinticinco años se ha pasado de un equipamiento reducido a una red extensa (de $5126 \mathrm{~km}$ a $17021 \mathrm{~km}$ ), con neto predominio de las vías de tránsito libre, frente a las de peaje (alrededor sólo del 20\%). Eso confirma el protagonismo de las inversiones públicas frente a los capitales privados y concepción concreta en el enfoque del transporte. Esta red de VRGC constituye la base esencial por donde circula más del $60 \%$ de todo el tráfico rodado que utiliza la carretera, mientras que representa sólo $10,2 \%$ de las mismas. Sin que pueda indicarse que se han cubierto todas las necesidades, sí cabe decir que alcanzan las áreas más pobladas y que casi ninguna ciudad de más de 50.000 habitantes queda sin conectar directamente con ella, a la vez que su isocrona de acceso a esa red no sobrepasa a menudo los 10 minutos. Su disposición espacial es básicamente radial. Se ha reforzado ese modelo territorial previo (Serrano, 2008). La excepción más marcada son las que discurren por el Arco Mediterráneo (Serrano, 2012a). Igualmente, debe señalarse que los tramos viarios realizados durante los últimos años (2012-2014) responden a un modelo espacial más mallado. En su conjunto, todos permiten acortar sustancialmente los tiempos de viaje en casi todo el territorio español, posibilitando accesos cómodos y fáciles. Los desplazamientos de personas y mercancías se han multiplicado a la vez que han supuesto una ayuda apreciable para la mejor integración territorial, generalizando la interconexión nacional. Tras esas consecuencias directas, podrían añadirse otras indirectas e inducidas. Entendemos que 
poner en servicio semejante red viaria ha sido uno de los elementos esenciales favorecedores del crecimiento económico español, a la vez que sus rendimientos sociales son numerosos (Serrano, 2007). Eso no oculta la existencia de ciertos desajustes, aspectos discutibles realizados que, cara al futuro, conviene corregirlos en la medida que sea posible.

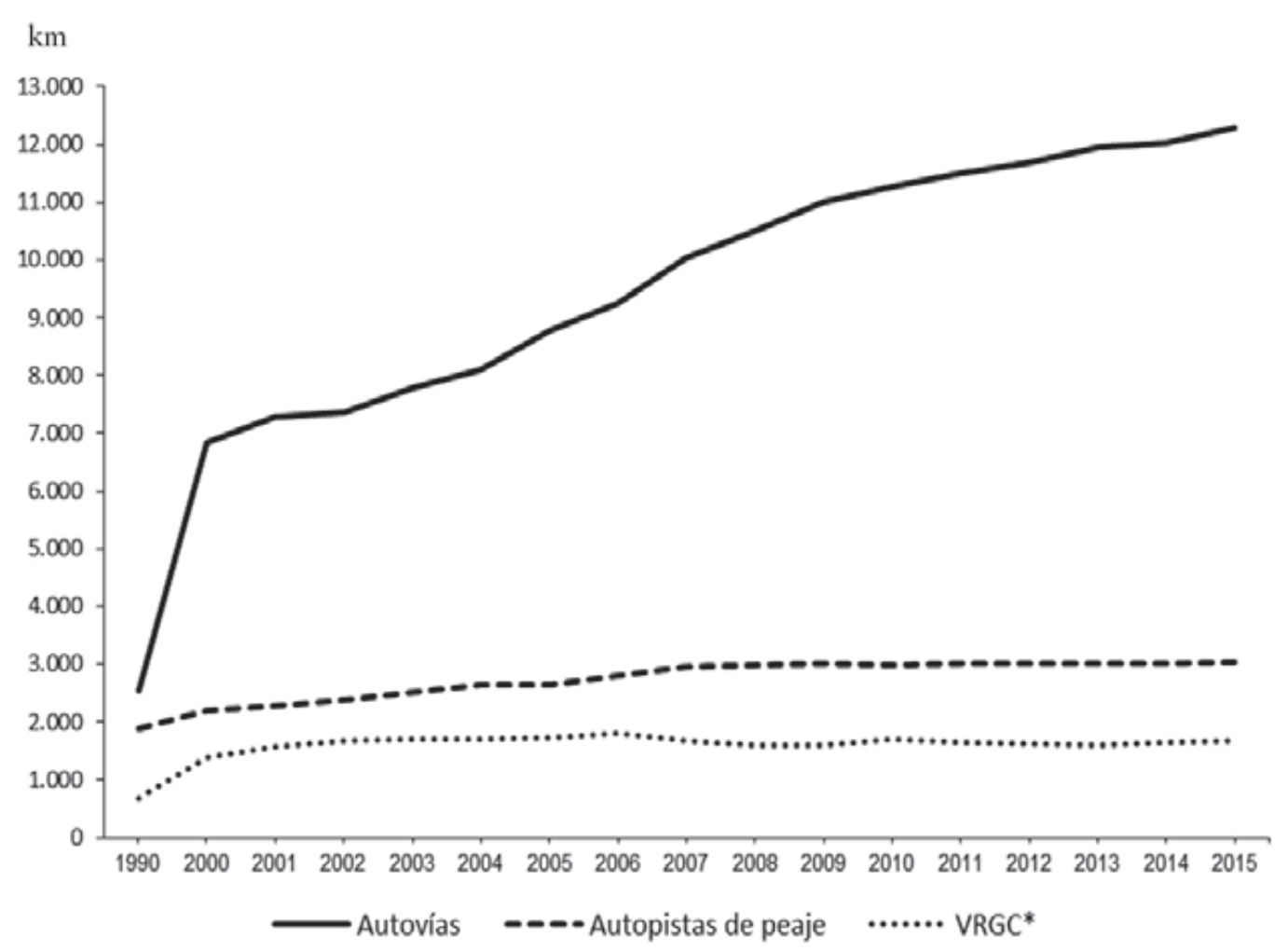

Fig. 2 - Evolución reciente de la red de Vías Rápidas de Gran Capacidad (VRGC) (autovías, autopistas de peaje y otras vías de gran capacidad).

Fig. 2 - Recent evolution in the High Capacity Highways (HCH) network (highways, toll roads and other high-capacity roads).

Fuente: Elaboración propia sobre datos del Ministerio de Fomento, Anuarios. Dirección General de Carreteras* A partir de 2015 se modifica la denominación de multicalzada por la de multicarril; aunque todas son VRGC

Seguidamente se detallan unas breves reflexiones: es discutible el modelo mayoritario elegido de VRGC libres, frente al pago directo de uso a través de las concesionarias. No en balde, predominan en el planeta otros modelos de peaje. En su conjunto, numerosas cuestiones quedan implícitas, tales como el impulso de mayor utilización que generan, de lo cual se derivan consecuencias de orden ecológico, etc. También sobre su viabilidad financiera, pues cargan sobre el erario público su mantenimiento, por ejemplo. Desde una perspectiva global, resulta muy difícil calibrar si se ha alcanzado ya una situación de sobredotación de VRGC. El balance sería tan dispar como los criterios de medición utilizados. Desde luego, debe de tenerse claro que el proceso seguido no puede contemplarse como algo indefinido. El sistema existente, donde cada autoridad local o 
regional solicita su tramo de obra para que otro la pague, es inviable por insostenible. Criterios técnicos derivados de las IMD (intensidades medias diarias de tráfico), sólo deberían dejarse de lado por circunstancias concretas singulares y estratégicas, o de marcada necesidad social y de reequilibrio territorial. Las áreas periurbanas de las aglomeraciones urbanas son las que ofrecen, por lo común, mayores desajustes de oferta/demanda. Algunas de esas mejoras, junto a la costosa tarea de conservación de la apreciable red en servicio, ya significan una carga elevada a asumir con los dineros públicos, exigiendo una partida notable de fondos.

B) Los ferrocarriles, al igual que en otros países, pero quizás con mayor intensidad en España, registraron un acusado declinar como modo de transporte durante las últimas décadas del siglo pasado. En ello concurren una serie de circunstancias de dispar naturaleza (Serrano \& García, 2010). Ante ese panorama de peor oferta, menor utilización de transporte de pasajeros y mercancías, y mayores déficits, las inversiones se redujeron; así se resintió la calidad en los servicios ofrecidos. En definitiva, se inició hace años una espiral de declive, en especial, frente al otro transporte terrestre que se afianzó: la carretera (Wais, 1974). Para hacer frente a ese panorama, se emprende el reto de dar un nuevo giro al transporte de viajeros por ferrocarril. Eso se lleva a cabo merced a la decisión de sucesivos programas de puesta en funcionamiento de la Alta Velocidad Española (AVE). Opción política que se impuso frente a la mejora sustancial de la red convencional existente (Serrano, 2000). Unos datos escuetos confirman ese devenir (figs. 3 y 4 ).

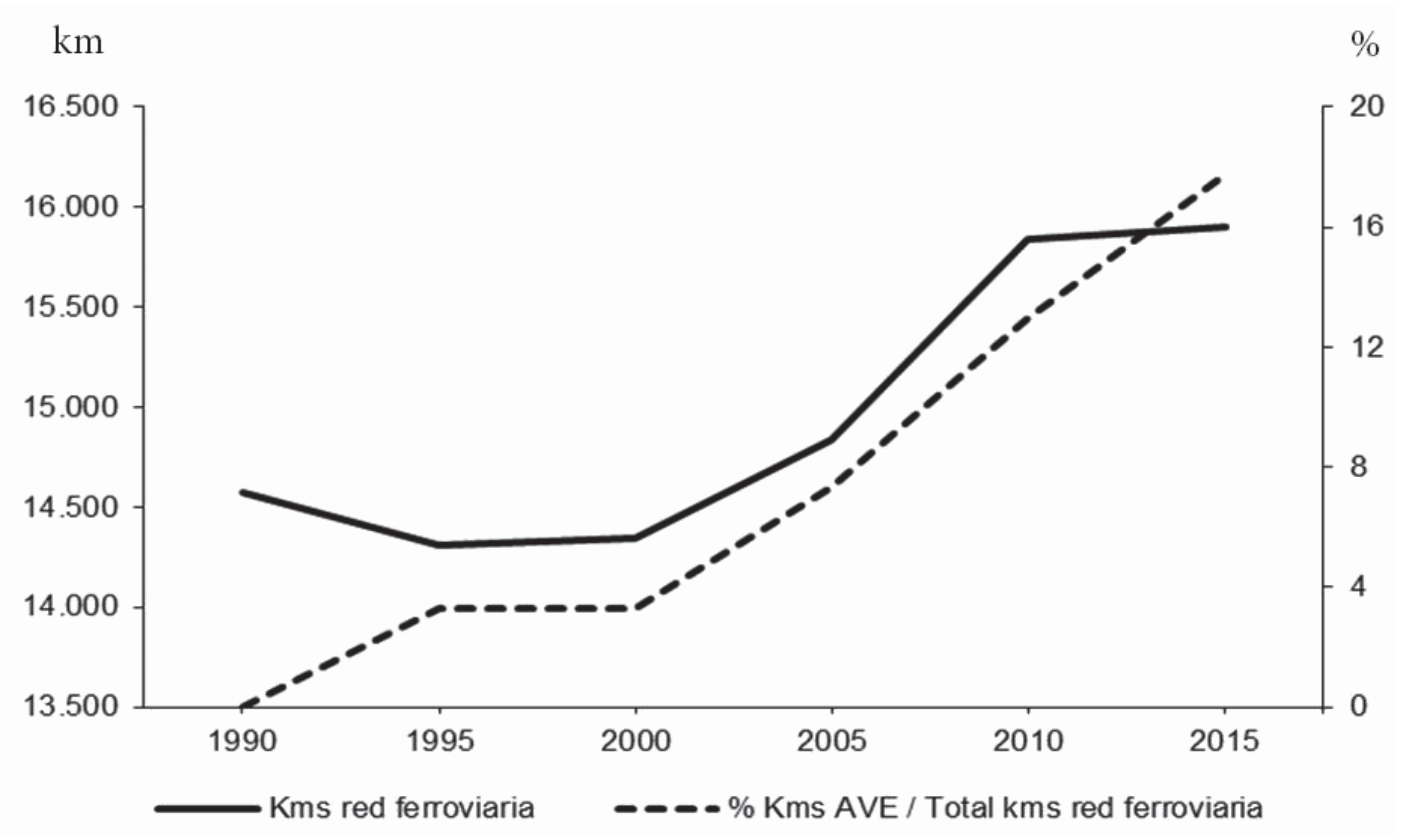

Fig. 3 - Evolución de la red de ferrocarriles en España.

Fig. 3 - Evolution of the rail network in Spain.

Fuente: Elaboración propia sobre datos del Ministerio de Fomento (2015) 


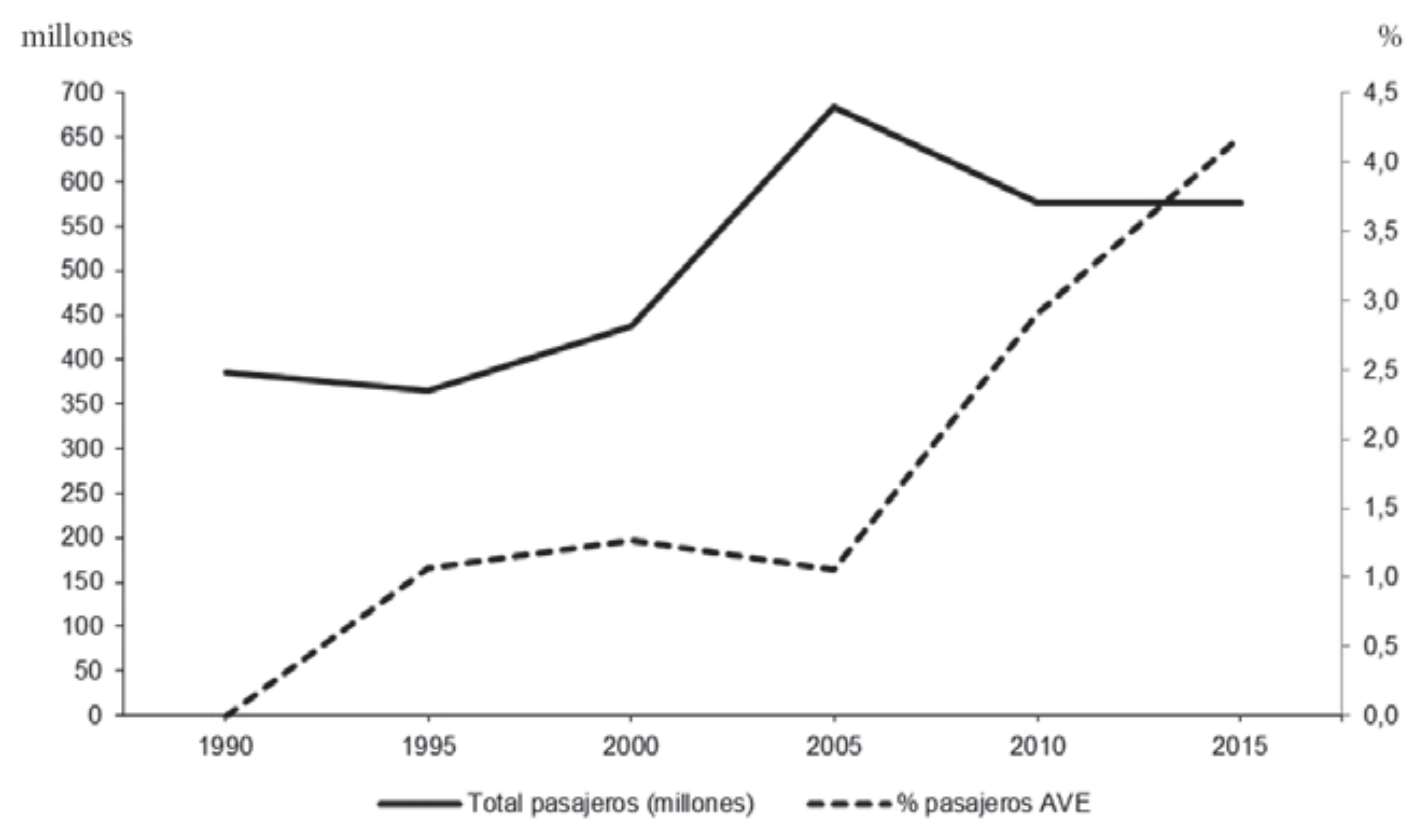

Fig. 4 - Pasajeros transportados en ferrocarril y porcentaje de usuarios de AVE.

Fig. 4 - Passengers transported by rail and percentage of AVE (Spanish high-speed) users. Fuente: Elaboración propia sobre datos del Ministerio de Fomento (2015)

Transcurridos cinco lustros, en lo que se refiere al transporte de viajeros, el tráfico total casi ha ascendido un cincuenta por ciento. Pero, aún no se ha remontado el bache que siguió a la actual crisis desde 2008. Las apreciables inversiones en ferrocarril, antes apuntadas, se han dirigido básicamente al AVE. En 2016 están operativos más de $3100 \mathrm{~km}$. Las vías de AVE enlazan una treintena de capitales de provincia (41 estaciones), a la vez que conecta ya casi todas las áreas más pobladas de España. Su tráfico de pasajeros ha pasado de 3,9 millones en 1995 a 24,14 en 2015. Sin embargo, su porcentaje de significación sobre el transporte total de pasajeros apenas supera el 4,19\%. Su mayor incidencia ha sido sobre los trayectos de largo recorrido (en dicho ámbito, sólo lo hicieron en trenes convencionales el 2,03\%); mientras que ha afectado menos a los desplazamientos regionales, pues mantiene el 4,11\%. Pero, en su conjunto, la mayor proporción global de usuarios del ferrocarril en España corresponde a los viajes de cercanías, que representaron dicho año 516,7 millones, es decir el 89,67\% del total.

El trazado de las vías del AVE ha seguido el ya clásico modelo radial, si bien ha precisado nuevos trechos; así se ha reforzado la centralidad capitalina. Acaso tal disposición permite enlaces más cómodos de las periferias entre sí, al pasar por el centro capitalino frente a otros planteamientos alternativos, pero de interés más dudoso para una armónica y equilibrada integración territorial española (Bel, 2011). Son frecuentes las reflexiones sobre su rentabilidad. A menudo, con criterios económicos, se argumenta su elevada inversión y la reducida rentabilidad social (Betancort \& Llobet, 2015). Se duda de ello, dado su copioso coste (evaluado en más de 50000 millones de euros). También se aduce que su puesta en servicio se ha realizado sin relación con otros modos de transporte, con los que concurre; caso de los vuelos internos o el propio transporte en autobús (De Rus, 2015b). Tal 
competencia desorganiza el mercado e introduce numerosas incertidumbres. Asimismo, la clientela conseguida hasta ahora no es tan elevada (Albalate \& Bel, 2011). Esto destaca al compararla con la de otros países donde opera (caso de Francia, y sobre todo Japón). La debilidad y distribución de los efectivos humanos en España condiciona ese aspecto sobremanera (Molino, 2016). Además, la red de ciudades y de aglomeraciones urbanas no podrá modificarse en los próximos años (Serrano \& Calmés, 1998). Acaso en una perspectiva futura, algunos de los elementos ahora considerados en ese balance económico, poco favorables hacia él, cambien. Ahora bien, también conviene valorar lo que ha ayudado su puesta en servicio en impulsar la industria española, relacionada con este tema, hacia el exterior. Otros numerosos aspectos deberían igualmente sopesarse a fin de alcanzar una valoración más ponderada. Desde luego, la decisión iniciada con la puesta en servicio del primer trecho, en 1992, tal vez debería haberse considerado mejor, dentro de una política de infraestructuras de transportes más global y completa. A partir de ahí, se tiene la sensación de que se practica una cierta huida hacia delante. A veces se dice que se ha creado una ficción nacional sobre sus bondades, incluso se lo califica de autoengaño colectivo; así, todas las regiones y ciudades desean su conexión a la red en proceso de configuración, sin medir más consecuencias que las de su propio interés. No obstante, se precisaría una argumentación contrafactual para saber cuáles hubieran sido los resultados de haber orientado las inversiones dedicadas al AVE en otra dirección; por ejemplo, remodelando la red ferroviaria convencional que, no se olvide, sigue adoleciendo de serios defectos (gran proporción de tramos con vía única, otra amplia parte de trechos sin electrificar, con acusados problemas de mantenimiento, abundancia de material obsoleto, ausencia de intermodalidad, etc.).

Igualmente, la ausencia de mejoras sustanciales en el transporte de mercancías es un tema que queda pendiente (Serrano, 2012b). Cara al devenir no es una cuestión baladí mejorar este apartado, pues la proporción de mercancías transportadas por ferrocarril es muy baja (3\%) y registra un descenso progresivo. Así se sobrecarga los otros modos de transporte, caso de la carretera. Igualmente deben eliminarse las distorsiones existentes ente RENFE (propietaria de la red de ferrocarriles) y ADIF (administración de infraestructuras ferroviarias), en especial cara a la mayor liberalización del sector en Europa prevista para 2020. La reducida atención al transporte de mercancías se aparta de las propuestas del Libro Blanco del Transporte de la Comisión Europea y nos aleja de lo que hacen otras economías más avanzadas.

Ahora bien, en conjunto, es indudable la mejora aportada por el AVE, reduciendo las isocronas de viaje, integrando mejor las áreas nodales españolas, ampliando numerosos ámbitos de influencia y vertebrando mejor el territorio. Aspectos todos que tienen una difícil evaluación precisa de impacto económico y de rentabilidad social (Bellet \& Alonso, 2016). Pero, no deben dejarse de lado las lagunas que deja, a la vez que permanecen buena parte de los déficits acumulados en décadas pasadas por la degradación del ferrocarril convencional.

En los tráficos de cercanías, sobre todo en las grandes Aglomeraciones Urbanas, se advierten situaciones muy contrastadas; frente a mejoras sustanciales hay carencias llamativas. 
C) El auge de la aviación civil y comercial ha sido reciente e intenso. Se hace sólo referencia al tráfico de pasajeros, dada la escasa significación que aún tienen las mercancías en este modo de transporte. Los datos de los pasajeros y aeronaves que utilizan los aeropuertos españoles son elocuentes (figs. 5 y 6 ).

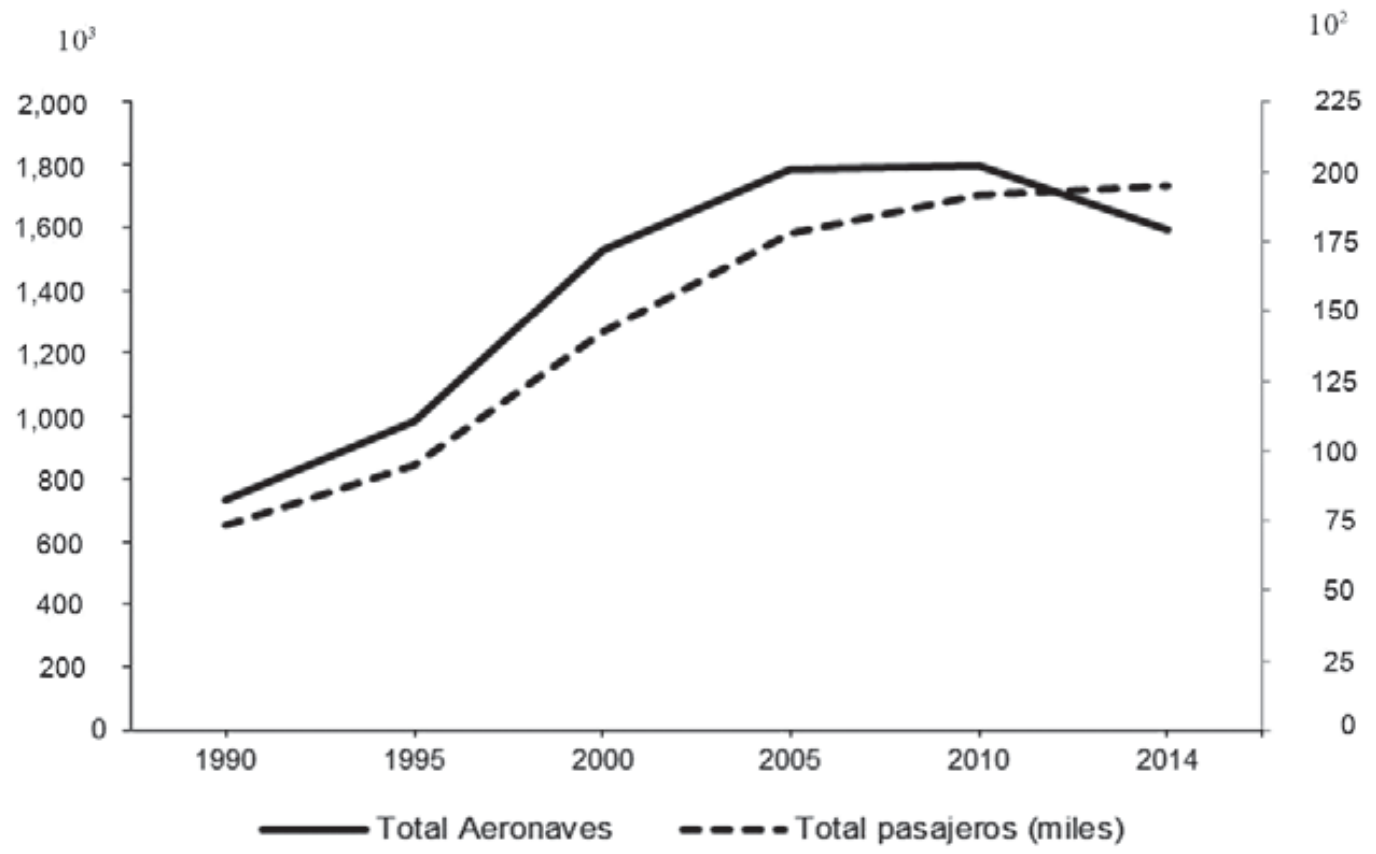

Fig. 5 - Evolución del tráfico aéreo (movimiento de aeronaves y pasajeros).

Fig. 5 - Evolution of air traffic (movement of aircraft and passengers).

Fuente: Elaboración propia sobre datos del Ministerio de Fomento (2015)

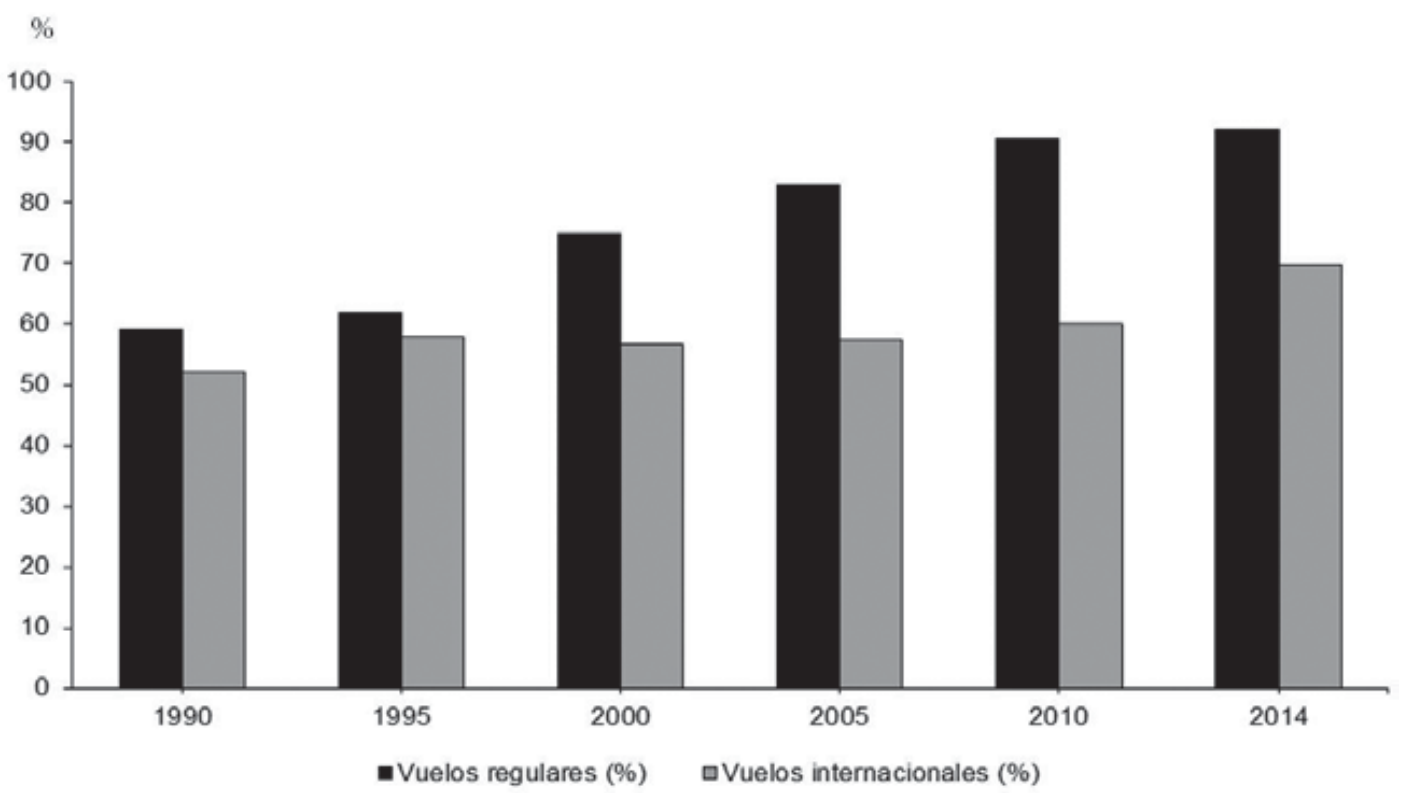

Fig. 6 - Porcentaje de vuelos regulares e internacionales.

Fig. 6 - Percentage of scheduled and international flights.

Fuente: Elaboración propia sobre datos del Ministerio de Fomento (2015) 
Durante el tiempo analizado se multiplica casi por tres el tráfico de pasajeros, a la vez que las aeronaves también aumentan con fuerza. El bache registrado en los años siguientes a 2008 parece superarse. Interesa comprobar dos elementos definidores del modelo de tráfico. Uno es el predominio creciente de vuelos regulares (algo común con las nuevas tendencias del tráfico mundial). El reciente auge del modelo LCC (low cost carries, compañías de bajo coste) ha impulsado a los viajeros y ha vigorizado los vuelos regulares, frente a los charters, a la vez que se ha consolidado el sistema de enlace PP (point to point), frente al Hub \& Sopkes (centro y radios). El otro, es el creciente protagonismo del tráfico internacional; lo cual se debe, en esencia, a dos elementos básicos. De una parte, a que la dimensión territorial española no es lo suficientemente amplia como para utilizar de manera más masiva este modo de desplazamiento con vuelos interiores. De otra, interesa destacar la significativa importancia del turismo foráneo en España, además de su progresiva integración en la economía mundial y la presencia de unas colonias copiosas de extranjeros residentes aquí, que periódicamente viajan hacia sus lugares de procedencia.

Todo el tráfico aéreo se canaliza a través de 48 aeropuertos y dos helipuertos. Su gestión la realiza AENA (Aeropuertos Españoles y Navegación Aérea). Su localización espacial casi se distribuye de manera regular por el conjunto español. Lo cual, estaría justificado si la densidad demográfica fuera homogénea. Además, debe tenerse presente que, en el último año de referencia, sólo 19 aeropuertos contabilizaron más de un millón de pasajeros. Hay numerosos centros con función local, provincial o regional, que apenas suman unas pocas decenas de miles de pasajeros al año (Serrano \& García, 2015). Así, frente a una docena de aeropuertos que registran ganancias, el resto sufre pérdidas. La gestión conjunta de su organización compensa los balances finales. La reciente privatización parcial de AENA parece haber enderezado la situación de fuertes deudas acumuladas en años pasados, cuando se acometieron llamativas e icónicas obras en algunos aeropuertos españoles. Los cercanos años de crisis, con el retroceso del tráfico generalizado, y la agudización de las pérdidas en muchos de ellos, han sido una llamada de atención para evaluar mejor nuevas inversiones. Es de esperar que en adelante AENA (tras su cambio estructural) mejore su eficacia. Desde luego, siempre, en el fondo, se llegará a una disyuntiva en la evaluación básica de los transportes al atender a su naturaleza económica, calibrando en especial costes y beneficios de cada aspecto, y a la función social que subyace detrás. Esta última no resulta sencillo delimitarla.

En otro orden de cosas, prever el ritmo de evolución del tráfico aéreo es arduo; de ahí la incógnita de conocer las necesidades aeroportuarias futuras. Pocos barruntaron el aumento espectacular del tráfico aéreo registrado de las últimas décadas (Cano, 1986). Acaso ni los más optimistas. La puesta en servicio de un aeropuerto no se improvisa. Pero eso no consuela, ni resuelve, cómo afrontar los desajustes existentes: numerosos aeropuertos que apenas funcionan, o lo hacen con continuas y abultadas pérdidas, $\mathrm{o}$ aquellos otros terminados y sin operar. La mayoría de los analistas coinciden en señalar la sobreoferta aeroportuaria existente y el solapamiento de sus áreas de influencia (Medrano, 2013); y ello debe servir de lección para actuaciones futuras. También la estacionalidad 
marcada de su tráfico es causa estructural constante de su menor utilización media. Por todo lo cual, a corto plazo, no parece necesario acometer nuevas inversiones cuantiosas. Solamente su readaptación tecnológica continua y su mantenimiento precisa significativas sumas.

D) El modo de transporte marítimo alcanza especial significación en los desplazamientos de mercancías; aunque es creciente el número de pasajeros, sobre todo debido al aumento de los cruceristas. Los primeros alcanzan en 2015 una cifra de 518,8 millones de total de mercancías (Tm) (cuadro III). Eso significa casi doblar durante los últimos lustros la cantidad inicial de referencia de 1990 (aumento del 102,46\%). Por su parte, el total de buques registrado sólo ha crecido un 30,5\%; consecuencia del ascenso de su dimensión media. De ahí se desprende la necesidad de aumentar y acondicionar las instalaciones portuarias para hacer frente a esas nuevas necesidades. Pero también confirma que, a menudo, se ha alcanzado un exceso de capacidad, que a veces se sitúa en casi un 50\% (Cerban \& Ortiz, 2015). Dentro del apartado del transporte de mercancías, si bien los graneles líquidos representan una parte significativa, aumentando su volumen (pasan de 112,43 millones de Tm a 146,73 millones, entre 1990 y 2015), su proporción sobre el total ha descendido al paso de los años. Del 46,20\% inicial, pasa al $32,39 \%$. De ahí se desprende que el petróleo y otros combustibles englobados en ellas, aunque mantienen especial significación, reducen su participación en el conjunto del trasiego portuario. De manera complementaria eso indica un neto incremento del volumen de las demás mercancías. Asimismo, debe destacarse, por lo que ello exige de actuaciones de renovación de las infraestructuras portuarias, el tráfico de contenedores. Su protagonismo en el transporte marítimo es creciente. Aquí los datos son elocuentes: durante los últimos 25 años se ha pasado de contabilizar 23,03 millones de Tm a 158,99 (un incremento del 690,36\%). Eso puede justificar algunas de las inversiones realizadas. Y todo apunta hacia su incremento futuro. En su conjunto, queda claro que todo el tráfico de mercancías con el exterior, y una parte del propio nacional (mediante el cabotaje, que en 2014 representó el 15,60\% del total) se realiza a través de este modo de transporte; de ahí su importancia estratégica.

Cuadro III - Evolución del tráfico marítimo.

Table III - Evolution of maritime traffic.

\begin{tabular}{cccccccc}
\hline & \multicolumn{3}{c}{ Mercancías } & \multicolumn{3}{c}{ Pasajeros (millones) } \\
\cline { 2 - 8 } & $\begin{array}{c}\text { Total } \\
\text { mercancías } \\
(\text { miles Tm) }\end{array}$ & $\begin{array}{c}\text { Movimiento de } \\
\text { Buques (miles) }\end{array}$ & $\begin{array}{c}\text { Graneles } \\
\text { líquidos } \\
(\text { miles Tm) }\end{array}$ & $\begin{array}{c}\text { Contenedores } \\
(\text { miles Tm) }\end{array}$ & Total & Exterior & Crucero \\
\hline 1990 & 256255 & 112,43 & 118,40 & 23033 & 16,44 & 4,32 & - \\
1995 & 299014 & 101,47 & 128,23 & 39361 & 13,62 & 2,51 & - \\
2000 & 348505 & 147,14 & 124,86 & 66860 & 19,63 & 3,52 & - \\
2005 & 456007 & 139,21 & 147,02 & 113837 & 26,94 & 8,63 & - \\
2010 & 442848 & 121,45 & 149,22 & 138436 & 26,38 & 4,60 & 7,18 \\
2015 & 518817 & 146,73 & 168,05 & 158991 & 31,08 & 4,95 & 8,65 \\
\hline
\end{tabular}


Por su parte, el tráfico de pasajeros también asciende y adquiere nuevas fórmulas. Su valor global confirma un ascenso, casi duplicado en esos años. La irrupción creciente de los pasajeros que utilizan los cruceros significa una nueva fórmula a la que interesa adaptarse, en especial dada la naturaleza y el peso turístico de España. Eso precisa la necesidad de ciertas obras de acondicionamiento. La denominada red de centros de interés del Estado está formada por 26 puertos. Sin duda, la especial configuración peninsular e insular de las costas españolas introduce ciertos condicionantes a la hora de su selección, para unos u otros menesteres. Pero, dada la internacionalización creciente del tráfico marítimo mundial, y la concentración de las principales rutas de tráfico, resulta poco comprensible mantener activos un número tan elevado de puertos, a veces poco distantes entre sí, que puede llevar a una equívoca e inoperante competencia interna. Menos aún lo es abordar nuevos proyectos. Dentro de la nueva realidad de infraestructuras de transporte alcanzada, es aconsejable priorizar las inversiones calibrando mejor los gastos. Los intereses y presiones regionales no deben ser motivo para emprender nuevas construcciones, ni ampliaciones sin mesura. La racionalización del gasto a realizar se impone.

\section{REFLEXIONES Y CONSIDERACIONES FINALES}

Como se ha indicado, las elevadas inversiones realizadas en infraestructuras de transporte durante los últimos lustros, además de incrementar de manera notable sus equipamientos (fig. 7), señalan apreciables desajustes, excesos de oferta y algunas inoperancias. Es fácil calibrar que todo ello ha constituido un ciclo de actuaciones dentro de un claro modelo productivo expansivo (Puig, 2011). Cara a los próximos años, todo apunta que se reducirán de manera significativa las cantidades disponibles de gasto. De ahí la conveniencia de reflexionar sobre los errores cometidos, corregir los desaciertos y caminar hacia otros planteamientos y objetivos. Las consecuencias de arrastre negativo derivadas de ese nuevo escenario para el sistema productivo son previsibles. Interesa evitar que se generen mayores debilidades del sistema de transportes alcanzado. Ante todo, conviene eludir la descapitalización del stock de infraestructuras existente, garantizando su conservación. Al respecto se añaden algunas consideraciones y reflexiones finales.

\section{Distribución territorial del gasto. Equilibrio e igualdad}

Tras la búsqueda de un beneficio común se justifica la distribución territorial homogénea de las inversiones. El sistema político actual de organización territorial español es muy descentralizado. Tras casi cuarenta años desde su inicio, las Comunidades Autónomas (CC.AA.) ofrecen un protagonismo creciente. Sus diferencias poblacionales, territoriales y demás elementos de dispar naturaleza son acusadas. Por lo común, su estrategia constante ha sido presionar para conseguir mayores cuotas de inversión desde el Estado. Para ello, cada una aduce los aspectos que pueden serle más ventajosos. Pero, lo que unas consigan de más, es a costa de que otras logran de menos (fig. 8). Así resulta muy difícil alcanzar decisiones finales que agraden a todos. 


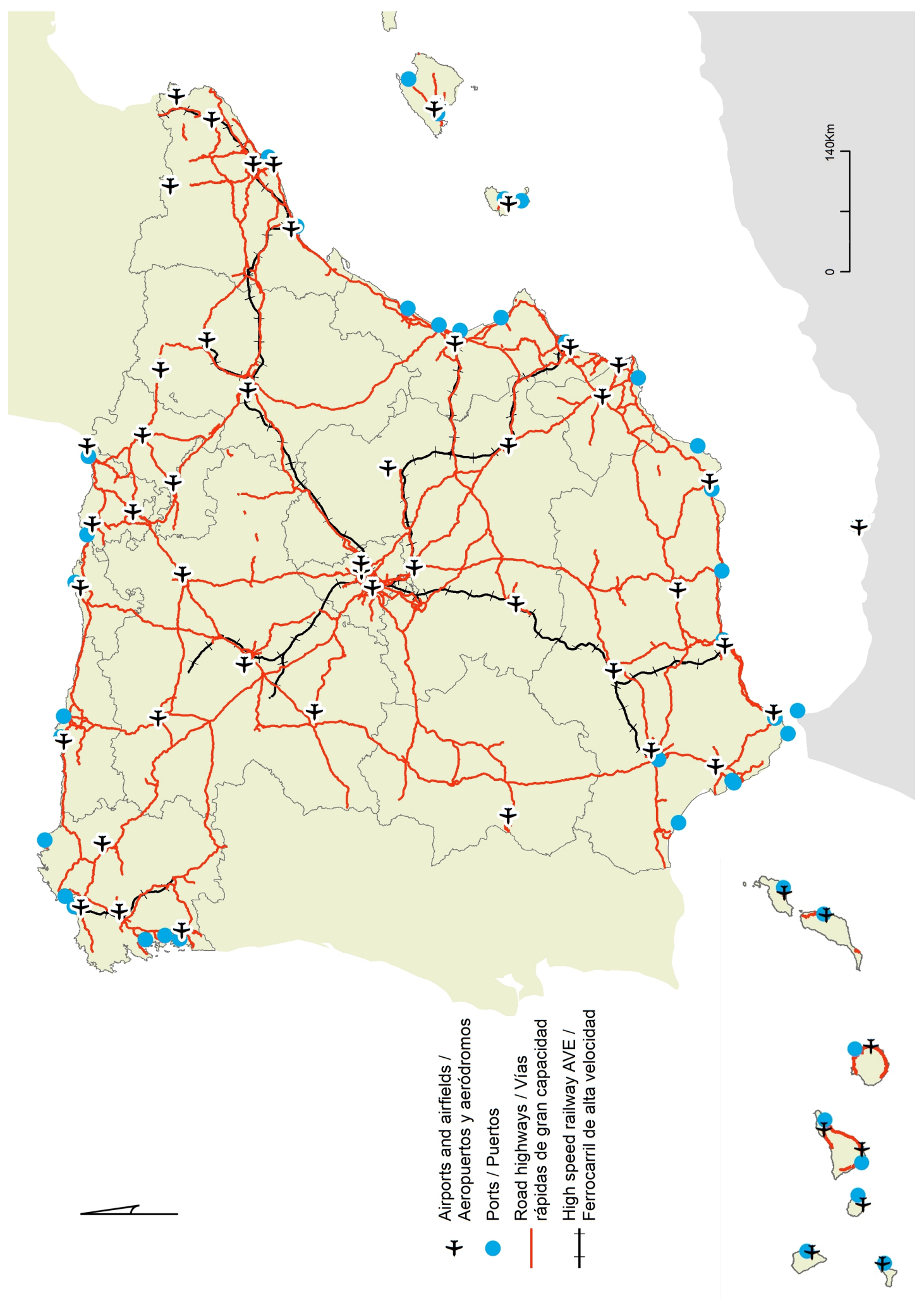

Fig. 7 - Infraestructuras de transporte básicas en España. Figura en color disponible en línea. Fig. 7 - Basic transport infrastructures in Spain. Colour figure available online. 


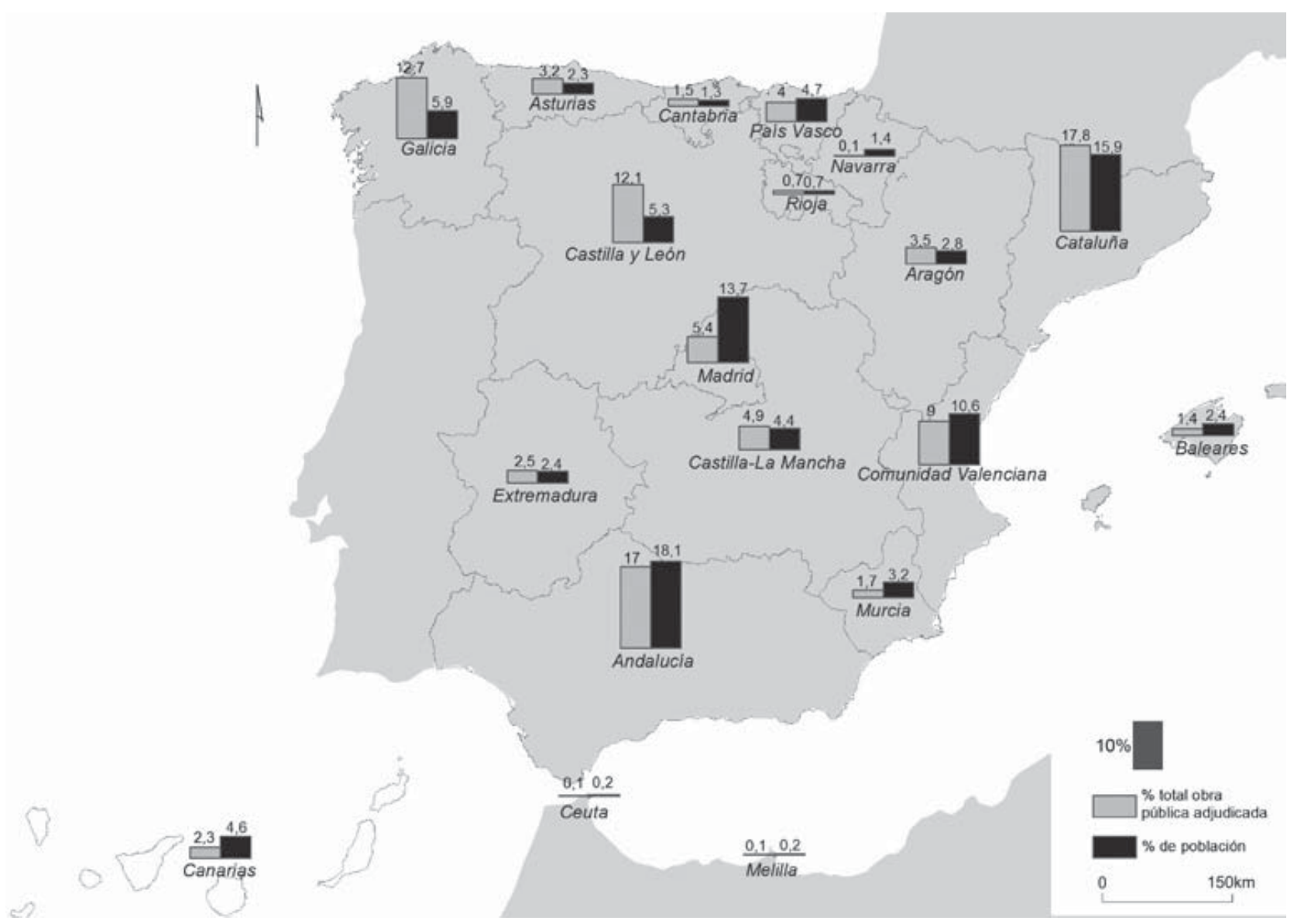

Fig. 8 - Distribución por CC.AA. de la obra pública en infraestructuras adjudicadas por el Ministerio de Fomento (2006 a 2015).

Fig. 8 - Distribution by Autonomous Communities of the public works in infrastructure awarded by the Ministry of Public Works (2006 to 2015).

Fuente: Elaboración propia a partir de: VV.AA. (2016)

No resulta sencillo territorializar todas las inversiones en infraestructuras de transporte. Entre otras razones porque pueden ser dispares los criterios seguidos. La figura 7 constituye un ejemplo de esa disparidad. A pesar de la cautela de las autoridades centrales, siempre pueden plantearse motivos de discrecionalidad y discriminación.

\section{Modos de transporte, volúmenes de tráfico y desajustes ¿Una realidad inducida?}

Si bien las cantidades de tráfico, tanto de pasajeros como de mercancías, han crecido de manera acusada, las proporciones encauzadas en los diferentes modos se han alterado sólo ligeramente (cuadro IV). 
Cuadro IV - Evolución del tráfico en diferentes modos de transporte, pasajeros y mercancías, interior e internacional. Valores porcentuales (2014).

Table IV - Evolution of traffic in different modes of transport, passengers and goods, interior and international. Percentage values (2014).

\begin{tabular}{crrrrrrrr}
\hline \multirow{2}{*}{ Modos } & \multicolumn{1}{c}{ Interior, viajeros } & \multicolumn{2}{c}{ Interior, mercancías } & \multicolumn{2}{c}{ Internacional, viajeros } & \multicolumn{2}{c}{ Internacional, mercancías } \\
\cline { 2 - 9 } & $\mathbf{1 9 9 0}$ & $\mathbf{2 0 1 4}$ & $\mathbf{1 9 9 0}$ & $\mathbf{2 0 1 4}$ & $\mathbf{1 9 9 0}$ & $\mathbf{2 0 1 4}$ & $\mathbf{1 9 9 0}$ & $\mathbf{2 0 1 4}$ \\
\hline Carretera & 89,39 & 82,76 & 75,51 & 82,76 & 68,58 & 42,33 & 13,78 & 13,87 \\
Ferrocarril & 7,14 & 3,50 & 5,81 & 3,50 & 3,99 & 0,31 & 1,66 & 1,12 \\
Marítimo & 0,46 & 13,72 & 18,63 & 13,72 & 2,58 & 5,11 & 84,44 & 84,91 \\
Aéreo & 3,01 & 0,02 & 0,05 & 0,02 & 24,85 & 52,25 & 0,12 & 0,10 \\
\hline Total & 100 & 100 & 100 & 100 & 100 & 100 & 100 & 100 \\
\hline \multicolumn{7}{c}{ Fuente: Elaboración propia sobre datos del Ministerio de Fomento (2015) }
\end{tabular}

Las gruesas sumas invertidas en infraestructuras de transporte sólo han permitido encauzar su aumento. Por tanto, cabe deducir que se ha afianzado el modelo preexistente. Así pues, la política de infraestructuras seguida ha servido, en esencia, para eso. Por ejemplo, las copiosas inversiones empleadas en el modo ferroviario, por ahora, no se han traducido en una modificación sustancial de la proporción de tráfico transportado, ni en su naturaleza. Dado el habitual efecto retardado de sus consecuencias (como apuntan Vickermann, Spiekermann \& Wegener, 1999), queda por ver si en adelante se registrarán alteraciones mayores. Sólo mediante el diseño y la práctica efectiva de una política integrada de transportes podrán emprenderse actuaciones de cambios estructurales en sus modos. Y deberá llevarse a cabo combinando de manera armónica el corto, medio y largo plazo temporal, con una exigencia creciente en la selección de las infraestructuras, destino de las inversiones públicas.

\section{Endeudamiento y disponibilidades económicas y presupuestarias futuras}

En este apartado los cambios recientes son acusados y preocupantes. El conjunto de la deuda de las Administraciones Públicas (AA.PP.) españolas se ha incrementado con vigor. Pasa, en cifras absolutas, de 378883 millones de euros en 2001, a 1 095,358 al finalizar 2016. En valores porcentuales eso significa subir del 35\% sobre el PIB nacional en 2001 al 100\% del mismo en 2016. Pero esas magnitudes son sólo parte de un todo más complejo, pues la deuda de las empresas españolas, en ese mismo tiempo, ascienden desde los 200000 millones a 914983 millones. Por su parte, la deuda de los hogares también ha crecido con fuerza: sube desde los 170000 millones en los comienzos de este siglo a 715653 en 2016. La suma de esos tres apartados confirma un incremento entre 2001 y 2016 que se eleva de 750000 millones de euros a 2,72 billones. Es decir, esta última magnitud equivale a más de 2,5 veces el conjunto del PIB nacional.

Es cierto que en esas cantidades se engloban elementos dispares, poco comunes entre sí. A la vez, su procedencia, posesión y plazo de amortización difieren. Asimismo, su aumento sólo se ha debido, en una pequeña parte, a las inversiones específicas realizadas en infraestructuras de transporte. Pero, sus magnitudes conjuntas confirman una pers- 
pectiva global de endeudamiento intenso. Igualmente conviene añadir que su aminoración reciente ha sido leve (entre 2012 y 2016 se ha reducido en menos de 70000 millones de euros). Ahora bien, esa reducción corresponde sólo a la tarea conseguida por las empresas y los hogares, mientras que la generada por las AA.PP. no ha cesado de ascender. Así, entre 2007 y 2017 aumenta en 713636 millones de euros (esto significa multiplicar la cifra inicial por 2,8).

Todo este entramado de endeudamiento corrobora una realidad comprometida. Por su parte, la evolución de la deuda correspondiente a las AA.PP. confirma la dificultad de seguir invirtiendo con fuerza en infraestructuras de transporte. El recurso de generar más deuda queda comprometido. Un panorama, pues, difícil. De ello se desprenden las limitaciones que, en adelante, tendrán las políticas presupuestarias pertinentes. De todas maneras, interesa también tener en cuenta otro aspecto destacado inherente con las inversiones en infraestructuras de transporte, nos referimos a los retornos fiscales derivados de estas inversiones (cuadro V).

Cuadro V - Desglose de los retornos fiscales en el caso de la inversión en infraestructuras.

Recaudación fiscal en porcentaje sobre el PIB.

Table V-Breakdown of fiscal returns in the case of infrastructure investment. Tax collection as percentage of GDP.

\begin{tabular}{lc}
\hline Recaudación directa, IVA & $\mathbf{\%}$ \\
\hline Aumento de recaudación por producciones inducidas & $\mathbf{0 , 2 1}$ \\
\hline - Impuestos netos sobre consumos intermedios & \\
- IRPF sobre remuneración de asalariados & 0,01 \\
- Cotizaciones sociales & 0,05 \\
- Impuestos sobre sociedades & 0,11 \\
- Prestaciones por desempleo & 0,03 \\
Suma & 0,21 \\
Aumento total de la recaudación & $\mathbf{0 , 4 1}$ \\
\hline
\end{tabular}

Fuente: VV.AA. (2013, p. 12)

Aunque las estimaciones aportadas admiten matices y ciertas correcciones puntuales, es evidente que sus proporciones regulares de retorno alcanzan porcentajes destacados. Eso debe añadirse al complejo efecto multiplicador inherente a estas inversiones, lo cual debe tenerse presente a la hora de fijar las futuras cantidades a invertir en este apartado de las infraestructuras. Si las disponibilidades de financiación pública no permitiesen emprender ciertas inversiones necesarias, acaso ayude la colaboración de la participación privada.

\section{Hacia una nueva política de infraestructuras}

Es fácil compartir la idea de que todo el sistema productivo tiene como finalidad, en última instancia, la felicidad de los individuos (De Rus, 2015a). El problema se presenta 
al definir el camino a seguir para alcanzarla. Toda política, aplicada a los variados órdenes de la vida, supone una opción de ideas, modelos y proyectos, propuestos por las diferentes ideologías. La gran contradicción que encierra el sistema liberal (predominante en el conjunto de nuestro entorno de la Unión Europea) es cómo hacer compatible sus principios básicos (esencia del liberalismo) con la intervención de los poderes públicos. Ante eso se abren diferentes opciones de confianza en las tareas de planeamiento: desde aquellos que consideran que se puede intervenir de manera profunda, hasta quienes son escépticos hacia sus resultados (Rullán, 2014).

En un plano teórico, el diseño de políticas de inversión, en este caso de infraestructuras, incumbe, en última instancia, a la autoridad soberana: el Estado, si bien dicha soberanía se ve contestada e influida dentro del marco de globalización y de descentralización crecientes. Es fácil convenir que la red de infraestructuras generales y comunes le corresponde a él organizarlas y planificarlas, aunque en su construcción, mantenimiento y operatividad pueden participar empresas privadas con diferentes grados de implicación y riesgo. Pero, en la práctica, su tarea se encuentra mediatizada por la fortaleza y estabilidad que tienen los gobiernos al ejecutar políticas concretas, dentro siempre de una realidad económica y productiva cambiante y variable. A eso se añade, en el caso de España, que la diversidad de intereses de las CC.AA. a veces puede comprometer actuaciones de interés global. Tal aspecto, a menudo, lleva a una separación clara entre quien pide la inversión y quien la paga; lo cual facilita desembocar en algunos casos hacia una rentabilidad social poco efectiva.

Por todo ello, se entiende que los planes de infraestructuras realizados no van, por lo común, más de allá de programas donde se recogen buenas intenciones. Eso no quiere decir que todos hayan sido iguales; nos referimos al Plan Director de Infraestructuras (1993-2007) (MOPT, 1993); Plan Estratégico de Infraestructuras y Transportes (2005-2020) (Ministerio de Fomento, 2004); o el más reciente: Plan de Infraestructuras, Transporte y Vivienda (2012-2024) (Ministerio de Fomento, 2013). Existen apreciables diferencias entre ellos, si bien se advierten ciertas continuidades. Suele partirse de la base de que la política de infraestructuras necesita de la ingeniería, el derecho y la economía. Nos permitimos añadir que también la Geografía puede contribuir con su mejor conocimiento del territorio, en sus dispares, pero complementarios apartados. El desarrollo de esa política seguirá unas fases: la planificación debe abarcar asimismo su regulación y posterior evaluación; a lo cual sigue la propia construcción y explotación de esas infraestructuras.

Un defecto constante atribuido a las políticas de transporte seguidas en España es su débil criterio económico y de coordinación intermodal (De Rus, 2015a), debido a la carencia de cultura económica, basada en la comparación de los beneficios y los costes sociales. El recurrir con preferencia a estudios de impacto (multiplicadores de actividades) no es suficiente. Incluso, mal llevado puede ser empleado como pantalla de justificación. En ese sentido, se corre el riesgo de situarse en un fetichismo hacia la construcción de nuevas obras, pensando sólo en agrandar la oferta, sin evaluar de manera cabal las demandas. De ahí sólo hay un paso hacia generar costosas ineficiencias. Es probable, 
debido al umbral mínimo de equipamientos del que se partía, desear acortar distancias. Las abundantes ayudas comunitarias acaso también favorecieron ese proceder. Sin duda, los diferentes lobbies, empresariales y financieros, no han sido ajenos a ello. Pero, ahora se precisa un cambio de rumbo, ante un nuevo escenario.

\section{Los transportes y sus infraestructuras: ¿Un medio para facilitar el desarrollo o un fin en sí mismo?}

Es evidente que la mejora de las infraestructuras de los transportes y la facilidad de los desplazamientos ayudan a conseguir una mejor accesibilidad, lo cual facilita el funcionamiento del sistema productivo. Cuestión bien diferente es que exista un vínculo automático entre el aumento del transporte y el crecimiento y desarrollo económico. Todo parece indicar que, una vez alcanzado un cierto umbral en los equipamientos de infraestructuras, es otra la relación alcanzada de coste-beneficio y oportunidad. Entendemos que ese proceso se ha recorrido en España. Las décadas pasadas han sido de fuerte inversión y mejora en las infraestructuras. No debe olvidarse la elevada contribución de las copiosas sumas procedentes de los "fondos europeos" destinadas a estos fines; acaso estos han contribuido a ignorar su auténtico coste real. Pero ahora, alcanzado cierto estadio, conviene pasar a otra fase bien diferente.

Creemos que situarse en posturas extremas conduce a poco. Hace años se insistía con fuerza en la debilidad de las infraestructuras, su diferencia negativa con nuestros vecinos y la imposibilidad de conseguir así un desarrollo económico (Salmon, 1995). Ahora hay quienes realizan una crítica clara de lo realizado (OMM, 2013). Se califica de la manera más rigurosa, como si todo hubiese sido un derroche, una malversación continua, un despilfarro constante. Incluso se señala como causa destacada de la actual crisis económica (Marsal \& Vilanova, 2013). Eso no parece cabal. Se suele decir que han ayudado al boom de la construcción en general (Naredo, 2010). Es cierto que se han cometido errores puntuales, también se han tomado orientaciones equivocadas, o al menos discutibles (así lo anunciábamos en lo referente a la AVE, si bien con suma brevedad). Todo eso debe servir de ayuda cara al futuro. Un porvenir que deberá enfocarse desde otras perspectivas. Si de alguna manera se conviene que para algunos la construcción de infraestructuras ha sido un fin en sí mismo, ahora debería ser un medio para completar una realidad territorial que padece ciertos desajustes, algunos de ellos originados por enfoques desviados en determinadas infraestructuras.

Ante ese nuevo planteamiento interesa también considerar el beneficio alcanzado por numerosos intangibles favorables derivados del proceso inversor en infraestructuras. Unos son directos y otros indirectos, menos evidentes. Muchos creemos que tienen un lado predominante favorable, si bien no faltan los de signo contrario. Nos referimos, por ejemplo, entre los primeros, a la mayor integración y vertebración territorial de España (se ha conseguido una equidad de servicios de transportes más grande); en definitiva, todo ello ha supuesto un ejemplo práctico de solidaridad territorial. También eso ayuda a su apertura y permeabilidad hacia el exterior, mejorando su valorización geoestratégica 
en escalas más amplias (Reig, 2007). De manera añadida, merced a ese auge constructor, se ha creado e impulsado una serie de grandes empresas destacadas en esas tareas que hoy desempeñan actividades de ámbito mundial (Torres, 2009). Hoy conforman un grupo de multinacionales que destacan por su dinamismo y actividad ${ }^{\text {ii }}$. Suponen un apartado de los más sobresalientes y destacados de la economía española en el marco internacional (Dunning \& Lundan, 2008). De manera directa crean riqueza y originan un efecto multiplicador de vasto alcance. No debe olvidarse, como aspectos desfavorables, los efectos negativos medioambientales que han producido (Sanz et al., 2016). Unos transportes multiplicados consumen una proporción elevada de energía. El camino emprendido no puede continuar creciendo de manera indefinida. Conviene plantearse no aumentar los desplazamientos sustentados sólo en su mayor facilidad operativa. A título de ejemplo, se calcula que desde 1992 la distancia media diaria recorrida por una persona en España ha pasado de $28 \mathrm{~km}$ a casi $50 \mathrm{~km}$. No tiene sentido seguir aumentándola de forma indefinida. Aproximar los lugares de producción a los de consumo reduciría los desplazamientos; eso sería positivo.

Por ello, la nueva política de infraestructuras deberá hacer frente a esos numerosos retos, con planteamientos y enfoques renovados. Entre los numerosos desafíos pendientes, se presume que uno destacado se refiere a la armonía de los intereses generales frente a los territoriales (Méndez, 2014). También, en su conjunto, la reducción de inversiones en este apartado conllevará debilidades en la recuperación económica, pues el conjunto del sistema productivo se ha sustentado con fuerza en él (Pareja-Eastway \& Turmo, 2013). Enunciar la puesta en marcha de un nuevo sistema de producción resulta sencillo, no tanto ponerlo en práctica.

\section{REFERENCIAS BIBLIOGRÁFICAS}

Albalate, D., \& Bel, G. (2011). Cuando la economía no importa. Auge y esplendor de la alta velocidad en España [When the economy does not matter. Boom and splendor of high speed in Spain]. Revista de Economía Aplicada, 55(XIX), 171-190.

Balmaseda, L. (2002). La burbuja inmobiliaria [The housing bubble]. Madrid: BBVA.

Bel, G. (2011). España, capital París. Origen y apoteosis del Estado Radial: del Madrid sede cortesana a la capital total [Spain, capital Paris. Origin and apotheosis of the Radial State: from the Madrid courtier seat to the total capital]. Barcelona: Destino.

Bellet, C., \& Alonso, P. (2016). Proyectos urbanos incompletos. Vacíos urbanos en la Zaragoza post-AVE [Incomplete urban projects: urban voids in post-high speed train Zaragoza]. Boletín de la Asociación de Geógrafos Españoles, 70, 285-304. doi: 10.21138/bage. 2172

Betancor, O., \& Llobet, G. (2015). Contabilidad financiera y social de la Alta Velocidad en España [Financial and social accounting of the High Speed in Spain]. Madrid: FEDEA.

Biehl, D. (1991). The role of infrastructure in regional development. In R. W. Vickerman (Ed.), Infrastructure and Regional Development (pp. 9-35). London: Pion.

Campos, J. L. (2008). La burbuja inmobiliaria española [The spanish housing bubble]. Barcelona: Marcial Pons.

Cano, G. (1986). Aproximaciones al Análisis Geográfico Regional [Approaches to Regional Geographic Analysis]. Sevilla: Universidad de Sevilla. 
Cerban, M., \& Ortí, M. (2015). Infraestructuras portuarias. Análisis del sistema Portuario Español. Contexto Internacional y reformas propuestas [Port infraestructures. Analysis of the Spanish port sistem. International context and proposed reforms]. Madrid: FEDEA.

Chesnais, M. (1997). Le transport, élement d'une stratégie complexe [Transport, element of a complex strategy]. In Les transports (pp. 3-35). Paris: Armand Colin.

De Rus, G. (2015a). Análisis coste-beneficio del tren de Alta Velocidad en España [Analysis cost-benefit of the High Speed train in Spain]. Economía Aplicada, 3, 27-48.

De Rus, G. (2015b). La política de infraestructuras en España. Una reforma pendiente [Infraestructura policy in Spain. Pending reform]. Madrid: FEDEA.

Dunning, J. H., \& Lundan, S. M. (2008). Multinational Enterprises and The Global Economy. Cheltenham: Edward Elgar.

Feito, J. L. (2011). La competitividad de la economía española [The competitiviness of the spanish economy]. In VV.AA. (Eds.), Hacia una nueva política económica española. Diagnósticos, desafíos, estrategias [Towards a new Spanish economic policy. Diagnostics, challenges, strategies] (pp. 119-147). Madrid: Alianza Editorial.

Fernández, R. (2006). El Tsunami urbanizador español y mundial [The spanish and global developer Tsunami]. Madrid: Virus Editorial.

Flyvbjerg, B. M., Skamris, K., \& Buhl, S. L. (2004). What Causes cost Overrum in Transport Infrastructure Projects?. Transport Review, 24(1), 3-18. doi: 10.1080/0144164032000080494a

García, E. (1987). La política de obras y la política de transportes en España (Una sucinta visión histórica) [The policy of works and the policy of transports in Spain (A brief historical overview)]. Situación, 1, 35-46.

García, J., \& Más, M. (2004). La vivienda y el sector de la construcción en España [Housing and the construction sector in Spain]. Alicante: CAM.

Gerondeau, Ch. (1996). Les transports en Europe [Transports in Europe]. Paris: EDS Editeur Paris.

Graham, D. J. (2005). Wider Economic Benefits of Transports Improvements: Link Between Agglomeration and Productivity. Londres: Imperial College.

Harvey, D. (2007). Espacios del capital [Spaces of capital]. Madrid: Akal.
Izquierdo, R., \& Menéndez, J. Ma. (1987). Transporte, economía nacional y desarrollo regional [Transport, national economy and regional development]. Situación, 1, 5-22.

López L., \& Rodríguez, E. (2010). Fin de ciclo. Financiarización, territorio y sociedad de propietarios en la onda larga del capitalismo hispano (1959-2010) [End of cycle. financialization, territory and society of proprietors in the long wave of hispanic capitalism (1959-2010)]. Madrid: Traficantes de sueños.

Marsal, Mª. L., \& Vilanova, J. Mª (2013). Hegemonía y declive de un ciclo desarrollista ya destronado. Urbanismo y construcción en España, 1997-2007 [Hegemony and decline of an already deposed expansionist development cycle. Urban planning and construction in Spain between 1997 and 2007]. Biblio3W, XVIII, 1015. Retrieved from: http://www.ub.edu/geocrit/b3w-1015.htm

Medrano, C. (2013). Aeropuertos en España. Un análisis crítico de su gestión [Airports in Spain. A critical analysis of your management]. Madrid: Itaerea.

Méndez, R. (2014). Crisis económica y reconfiguraciones territoriales [Economic crisis and territorial reconfigurations]. In J. M. A. Puebla, \& J. L. S. Hernández (Coord.) Geografía de la crisis económica en España [Geography of the economic crisis in Spain] (pp. 17-38). Valencia: Universidad de Valencia.

Merenne, E. (1995). Géographie des transports [Geography of transport]. Paris: Nathan.

Merlin, P. (1991). Géographie, économie et planification des transports [Geography, economy and transport planning]. Paris: P.U.F.

Ministerio de Fomento (2015). Anuario Estadístico 2015 [Statistical yearbook 2015]. Madrid: Secretaría de Estado de Infraestructuras y Transportes. Retrieved from: https://www.fomento. gob.es/NR/rdonlyres/013B6EE3-871D-41188F74-1334BE86462A/143249/Anuario2015.pdf

Ministerio de Fomento (2013). Plan de Infraestructuras, Transporte y Vivienda (2012-2024) [Infrastructure, Transport and Housing Plan (2012-2024)]. Madrid: Secretaría de Estado de Infraestructuras y Transportes.

Ministerio de Fomento (2004). Plan Estratégico de Infraestructuras y Transportes, 2005-2020 [Strategic Plan for Infrastructure and Transport, 2005-2020]. Madrid: Secretaría de Estado de Infraestructuras y Transportes. 
MOPT (1993). Plan Director de Infraestructuras (1993-2007) [Director Plan of Infrastructures (1993-2007)]. Madrid: Secretaría General Técnica.

Molino, del S. (2016). La España vacía. Viaje por un país que nunca fue [The empty Spain. Travel for a country that was never]. Madrid: Turner.

Muñoz, A. (2013). Todo lo que era sólido [All that was solid]. Barcelona: Seix Barral.

Naredo, J. M. (2010). El modelo inmobiliario español y sus consecuencias [The Spanish real estate model and its consequences]. Boletín $C F+S$, 44, Tierra $y$ Libertad. Retrieved from: http://habitat.aq.upm. es/boletin/n44/ajnar.html

OMM (Eds.) (2013). Paisajes Desvastados. Después del ciclo inmobiliario: impactos regionales y urbanos de la crisis [Devastated Landscapes. After the real estate cycle: regional and urban impacts of the crisis]. Madrid: Traficantes de sueños.

Pareja-Eastaway, M., \& Turmo, J. (2013). La necesaria transformación del Modelo Productivo en España. El papel del territorio [The necessary transformation of the Productive Model in Spain. The Role of Territory]. Documents d’Anàlisi Geogràfica, 59(3), 455-479.

Pérez, J. (2013). Crisis económica y territorio: el impacto de la crisis sobre la desigualdad de rentas en las distintas regiones españolas [Economic crisis and territory: the impact of the crisis on income inequality in the different spanish regions]. Papeles de Economía Española, 135, 36-46.

Puig, A. (2011). El modelo Productivo español en el periodo expansivo de 1997-2007. Insostenibilidad y ausencia de política de cambio [The spanish productive model in the expansive period of 1997-2007. Unsustainability and absence of exchange policy]. Revista de Economía Crítica, 12, 64-68.

Quinet, E. (1992). Infrastructures de transport et croissance [Transportation Infrastructure and Growth]. Paris: Economica.

Reig, E. (2007). Competitividad, crecimiento y capitalización de las regiones españolas [Competitiveness, growth and capitalization of Spanish regions]. Madrid: Fundación BBVA-IVIE.

Salmon, K. (1995). The modern Spanish Economy. Transformation and integration into Europe. Londres, Pinter.

Sanz, A., Vega, P., \& Mateos, M. (2016). Las cuentas ecológicas del transporte en España [The ecological accounts of transport in Spain]. Madrid: Libros en Acción.
Seguí, J. Ma., \& Martínez, Ma. R. (2004). Geografía de los transportes [Geography of transport]. Palma de Mallorca: Universidad de las Islas Baleares.

Segura, F. (2016). La política de grandes infraestructuras de transporte en el Estado español: un despilfarro inmoral [The policy of large transport infrastructures in the Spanish State: an immoral waste]. Retrieved from: www.fuhem.es/ ecosocial/articulos.aspx?v

Segura, F. (2013). Infraestructuras de transporte, impacto territorial y crisis [Transport infrastructures, territorial impact and crisis]. In Observatorio Metropolitano de Madrid (Eds.), Paisajes Desvastados. Después del ciclo inmobiliario: impactos regionales y urbanos de la crisis [Devastated Landscapes. After the real estate cycle: regional and urban impacts of the crisis] (pp. 77-122). Madrid: Traficantes de sueños.

Segura, F. (2012). Infraestructuras de transporte y crisis. Grandes obras en tiempos de recortes sociales [Transport and crisis infrastructures. Great works in times of social cuts]. Madrid: Libros de acción.

Serrano, J. Ma. (2012a). Transporte de mercancías por ferrocarril en España; agotamiento de un modelo y su necesaria renovación. El difícil futuro [Railway shipping in Spain; exhaustion of a model and the need for renovation. The difficult future]. Boletín de la Asociación de Geógrafos Españoles, 60, 203-226.

Serrano, J. Ma . (2012b). Del arco al eje mediterráneo en España. Hacia la consolidación de un corredor de transportes [From the arc to the Mediterranean axis in Spain, towards the consolidation of a transportation corridor]. Finisterra - Revista Portuguesa de Geografia, XLVII(93), 85-107. doi: 10.18055/Finis1299

Serrano, J. Ma. (2008). Erreichbarkeit der Städtischen Agglomerationen Spaniens im strassennetz. Modelle und Engpässe [Access to the urban agglomeration of Spain in the street network. Models and bottlenecks]. In F. Harder, \& R. Schliephake (Eds.) Verkehrsgeographische Fallstudien in Europa und seinen Regionen [Traffic-related case studies in Europe and its regions] (pp. 33-48). Wurzburger: Geographische Manuskripte.

Serrano, J. Ma . (2007). Hacia una red mallada de vías rápidas de gran capacidad. El nuevo Plan Estratégico de Infraestructuras y Transportes 
[Towards a network of high-speed expressways. The new Strategic Infrastructure and Transport Plan]. Boletín de la Asociación de Geógrafos Españoles, 43, 173-196.

Serrano, J. Ma . (2000). El ferrocarril de Alta velocidad en España, evolución y perspectivas frente al tercer milenio [The High Speed Railway in Spain, evolution and prospects in the third millennium]. Nimbus, 5-6, 125-154.

Serrano, J. Ma., \& Calmés, R. (1998). L'Espagne. Du sous-développement au développement [Spain. From Underdevelopment to Development]. Paris: L'Harmattan.

Serrano, J. Ma., García, R., \& Gil, S. (2010). La política de transporte ferroviario en España. Los corredores de Alta Velocidad: sus potenciales y limitaciones [The politics of rail transport in Spain. The high-speed corridors: their potentials and limitations]. Scripta Nova. Revista Electrónica de Geografía y Ciencias Sociales, XIV(331), 20.

Serrano, J. Ma , \& García, R. (2015). Local low-traffic airports in Spain: problems and the necessary reorganisation of the Territorial network. Boletín de la Asociación de Geógrafos Españoles, 67, 251-74.

Taltavull, P. (2001). Economía de la construcción [Economy of the construction]. Madrid, Civitas.

Tamames, R. (1964). Estructura económica de España [Economic structure of Spain]. Madrid: Sociedad de Estudios y Publicaciones.

Thomson, J. M. (1976). Teoría económica del transporte [Economic Theory of Transport]. Madrid: Ed. Alianza Universidad.
Torres, E. (2009). Las grandes empresas constructoras españolas. Crecimiento e internacionalización en la segunda mitad del siglo XX [The big Spanish construction companies. Growth and internationalization in the second half of the 20th century]. Información Comercial Española, 649, 113-127.

Vergés, R. (2013). Crisis y stocks [Crisis and stocks]. Observatorio inmobiliario y de la construcción, 48, 52-59. Retrieved from: http://www.Observatorioinmobiliario.es/Revista/n48

Vickermann, R., Spiekermann, K., \& Wegener, M. (1999). Accessibility and Economic Developpement in Europe. Regional Studies Association, 33(1), 1-15.

VV.AA. (2016). Las inversiones en infraestructuras en España. Análisis y distribución territorial. Estudio de la última década (2006-2015) [Investments in infrastructure in Spain. Analysis and territorial distribution. Study of the last decade (2006-2015)]. Barcelona: Convivencia Cívica Catalana.

VV.AA. (2015). Contribución de las infraestructuras al desarrollo económico y social de España [Contribution of infrastructures to the economic and social development of Spain]. Madrid: ATKearney Consultor.

VV.AA. (2013). La inversión en infraestructuras públicas en España [Investment in public infrastructures in Spain]. Madrid: CEOE.

Wais, F. (1974). Historia de los ferrocarriles en España [History of the railways in Spain]. Madrid: Editora Nacional.

Según ADIF, los pasajeros en 2015 fueron 33,42 millones http://www.adifaltavelocidad.es/es ES/infraestructuras/lineas de alta velocidad/lineas de alta velocidad.shtml

ii Sólo las principales firmas: ACS, Ferrovial, OHL, Acciona, FCC y Sacyr, acumulaban en 2015 más de 70000 millones de euros en contratos externos; una cifra creciente que representa más del 87\% del total de su cartera. Desde 1985 han participado en proyectos en los cinco continentes (más de 90 países), por una suma superior a los 250000 millones de euros. Evaluar sus beneficios para la economía española, en sus diferentes apartados, es algo que no debe dejarse de lado. 